\title{
Metabolic engineering strategies for microbial synthesis of oleochemicals.
}

\author{
Brian F. Pfleger ${ }^{\mathrm{a}, \mathrm{b}, *}$, Michael Gossing ${ }^{\mathrm{c}}$, and Jens Nielsen ${ }^{\mathrm{c}}$
}

a

Department of Chemical and Biological Engineering, University of Wisconsin-Madison, Madison, WI, United States

b Microbiology Doctoral Training Program, University of Wisconsin-Madison, Madison, WI, United States

c Department of Biology and Biological Engineering, Chalmers University of Technology, Göteborg, Sweden

* Corresponding author. 3629 Engineering Hall, 1415 Engineering Drive, Madison, WI 53706, United States. Phone: +1 608890 1940. Fax: +1 608 262-5434. E-mail address: pfleger@engr.wisc.edu. 


\begin{abstract}
:
Microbial synthesis of oleochemicals has advanced significantly in the last decade. Microbes have been engineered to convert renewable substrates to a wide range of molecules that are ordinarily made from plant oils. This approach is attractive because it can reduce a motivation for converting tropical rainforest into farmland while simultaneously enabling access to molecules that are currently expensive to produce from oil crops. In the last decade, enzymes responsible for producing oleochemicals in nature have been identified, strategies to circumvent native regulation have been developed, and high yielding strains have been designed, built, and successfully demonstrated. This review will describe the metabolic pathways that lead to the

10 diverse molecular features found in natural oleochemicals, highlight successful metabolic engineering strategies, and comment on areas where future work could further advance the field.
\end{abstract}

\title{
Graphical Abstract
}

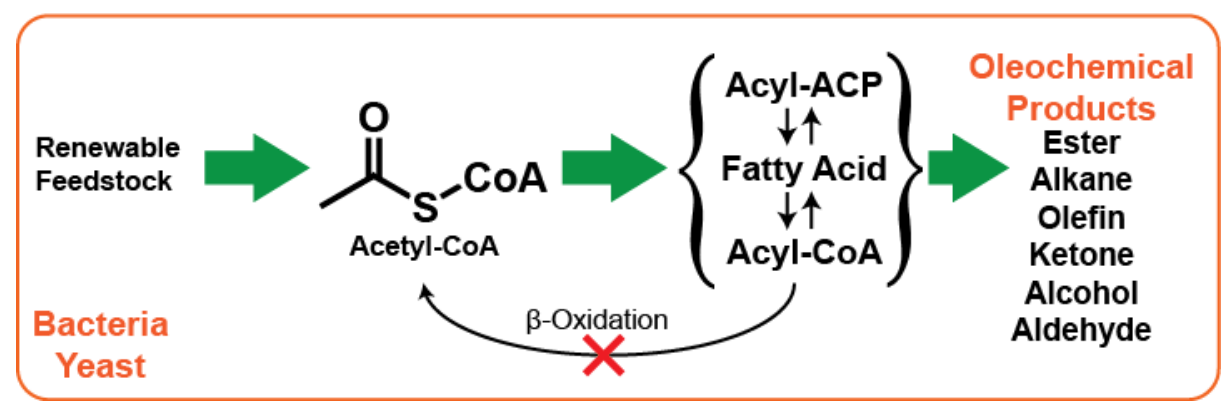


Keywords:

Oleochemical

Fatty acid

$5 \quad$ Metabolic Engineering

Synthetic Biology

Biodisesel 


\section{Abbreviations:}

- $\mathrm{Mt}$

- $\mathrm{CoA}$

- 2-MP-CoA

- 3-MB-CoA

- 2-MB-CoA

- ACCase

- FFA

- FAEE

- FAME

- AAce

- MK

- Alk
Metric ton

Coenzyme A

2-methyl-propionyl-CoA

3-methyl-butyryl-CoA

2-methyl-butyrl-CoA

Acetyl-CoA carboxylase

Free fatty acid

Fatty acid ethyl ester

Fatty acid methyl ester

Acetate acyl ester

Methyl-ketone

Alkane 


\section{Introduction}

Oleochemicals are a class of aliphatic molecules derived from lipids (Biermann et al., 2011). Oleochemicals are used in a wide range of applications including transportation fuels, consumer products (e.g. cosmetics, shampoo, cleaners), and industrial products (e.g. surface

5 coatings, paints, lubricants, bioplastics). The most common oleochemicals are surfactants (e.g. sodium dodecyl sulfate) and biodiesel. Currently, the majority of oleochemicals are made from inexpensive lipid sources such as plant oils and animal fats. Growing demand for oleochemicals, and in particular biodiesel, has led to an increased production of plant oil crops and raised concern about the sustainability and environmental impact of oil seed production (Fargione et al.,

10 2008). Consequently, interest in identifying alternative oleochemical feedstocks, such as waste oil, meat processing waste, and algal lipids has grown. Alternatively, a wide range of feedstocks, including sugar crops, lignocellulosic biomass, natural gas, and/or carbon dioxide, could be used if microbial biocatalysts were developed via metabolic engineering (Keasling, 2010). Over the last decade, tremendous progress has been made in identifying critical enzymes, increasing

15 understanding of how lipid synthesis is regulated, and demonstrating successful metabolic engineering strategies (Janßen and Steinbüchel, 2014; Klug and Daum, 2014; Lennen and Pfleger, 2013). This review will provide an overview of oleochemical metabolism, highlight some of the successful metabolic engineering approaches, and provide a perspective on remaining challenges in the field.

\section{Current and Future Oleochemical Markets}

Currently, plant oils are the major feedstock for oleochemical production. As a consequence of growing oleochemical demand, production of plant oils has steadily increased (up 14\% from 148.96 Mt in 2010-11 to $169.56 \mathrm{Mt}$ in 2013-14) and is expected to increase further 
(up $28 \%$ by 2023 relative to the 2011-2013 average). Usage of plant oils can be divided into three categories: food, biodiesel and oleochemicals. Of the $157 \mathrm{Mt}$ of plant oil consumed in 2012-13, 77\% were used for production of food, $12 \%$ were used for production of biodiesel, and the remaining 11\% for production of oleochemicals (OECD, 2014; Oilseeds: World Markets and

5 Trade, 2014). Production of vegetable oil is generally considered environmentally unsustainable, due in part to deforestation associated with establishing new palm and soy oil plantations and the long time required to repay the carbon debt associated with the establishing new oil crops (Fargione et al., 2008). Additionally, the use of edible vegetable oil for industrial oleochemical production adds to the debate over whether land should be farmed for fuel or food. This problem 10 will continue to grow in the near future since the percentage of global vegetable oil production used for biodiesel is projected to increase from 12\% in 2012 to 14\% in 2023 (OECD, 2014).

Two potential solutions include the production of lipids in photoautotrophic algae or conversion of plant biomass using engineered microbes. Building upon the early work of the Aquatic Species Program at the National Renewable Energy Laboratory (Sheehan et al., 1998),

15 significant progress has been made using systems biology, synthetic biology, and metabolic engineering to increase the production of algal lipids (Radakovits et al., 2010). Despite these successes, many challenges to algal lipid production remain (Wijffels and Barbosa, 2010). Alternatively, technologies developed for the production of cellulosic ethanol can be utilized to produce biodiesel and oleochemicals with the assistance of novel microbial catalysts. In this 20 approach, microbes are engineered to retask pathways traditionally reserved for production of structural or energy storage molecules for producing specific oleochemical products. The diversity of pathways for producing oleochemical products has been cataloged by many past 
reviews (Janßen and Steinbüchel, 2014; Lennen and Pfleger, 2013; Peralta-Yahya et al., 2012; Shi et al., 2011; Zhou et al., 2014).

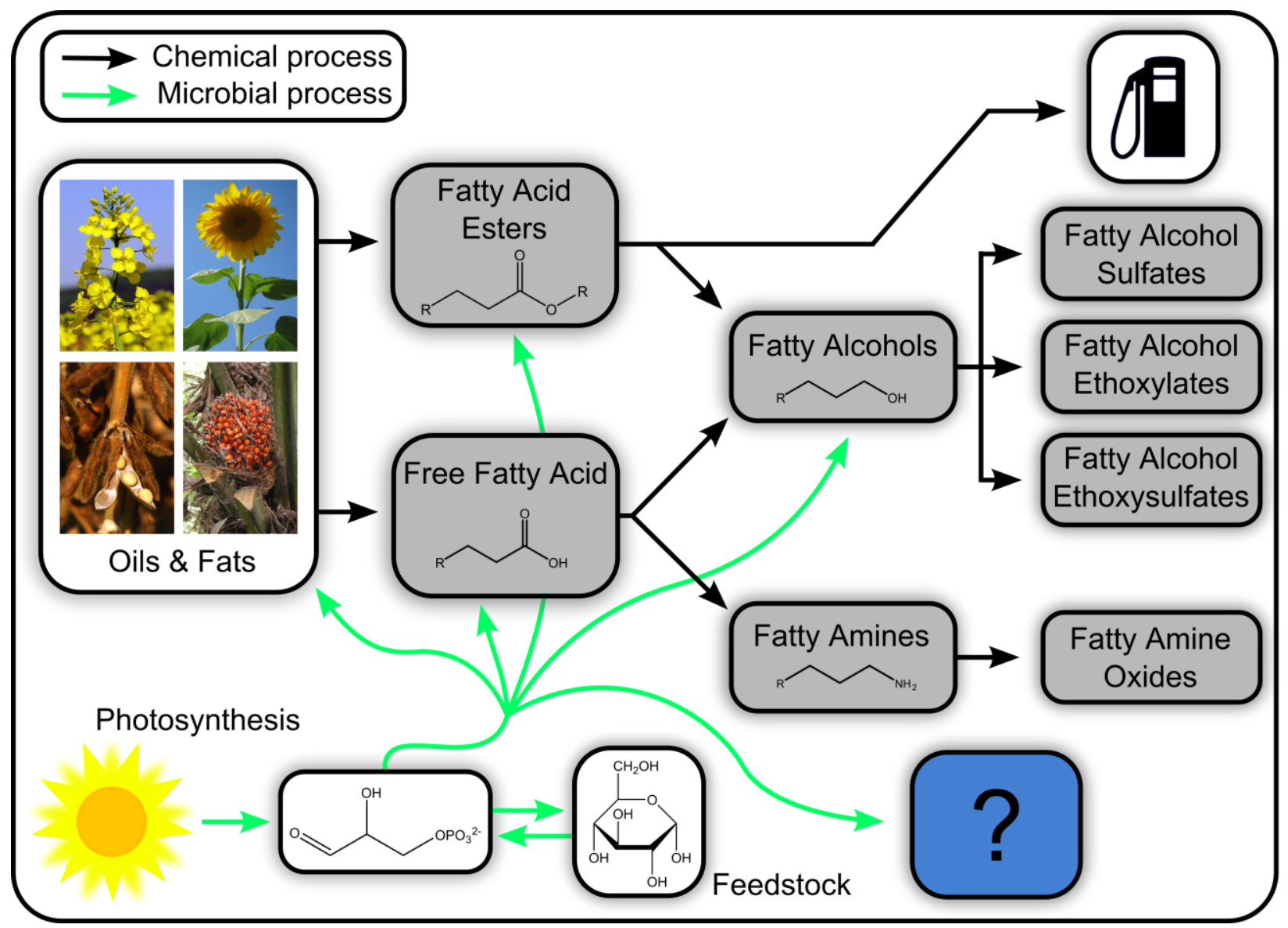

Figure 1. Oils \& fats are currently the primary feedstock for oleochemical production. Free

5 fatty acids and fatty acid esters are the raw materials used to synthesize oleochemicals. These intermediates are produced by saponification or transesterification of oils and fats, respectively. Fatty acid esters are used as biodiesel, a renewable transportation fuel with properties comparable to conventional petrodiesel. Fatty acid esters and free fatty acids are converted to fatty alcohols or fatty amines which are intermediates for production of various surfactants such as fatty alcohol sulfates and fatty alcohol ethoxysulfates (anionic) or fatty alcohol ethoxylates and fatty amine oxides (non-ionic). Engineered microbes have the potential to produce many of the intermediates in this scheme from renewable resources. These microbes are either directly photoautotrophic or use plant biomass as a feedstock (such as lignocellulosic sugars). 


\section{Oleochemical metabolism}

Oleochemicals are synthesized via enzymatic reactions that use free fatty acids or acyl-

5 thioesters as substrates. Therefore, metabolic engineering strategies for producing oleochemicals by microbial cells begin by redirecting carbon flux from fatty acid metabolism towards a desired product. Fatty acid metabolism is a complex, highly-regulated network of enzymatic reactions that operates on acyl-thioester intermediates (Chan and Vogel, 2010; Janßen and Steinbüchel, 2014; Tehlivets et al., 2007; Zhang et al., 2008). The network uses an iterative reaction pathway

10 to produce a wide-range of acyl-chains from a small set of building blocks. The biosynthetic pathway for any oleochemical can be divided into four processes: chain initiation, chain elongation, chain termination, and chain modification. Each of these processes provides opportunities for customizing a pathway to produce a novel oleochemical. Figure 2 highlights the options provided by each of these four processes. This review will focus on the two common

15 metabolic engineering hosts, Escherichia coli and Saccharomyces cerevisiae. The differences between and general advantages of these microbes for producing chemicals have been described elsewhere (Na et al., 2010; Woolston et al., 2013). In terms of oleochemicals, each synthesizes fatty acids from a distinct pathway (bacterial type II FAS and fungal type I FAS, respectively), that provides advantages depending on the desired oleochemical target. These advantages will be

20 highlighted below.

(Next Page) Figure 2. Oleochemical Metabolism. The molecular features of oleochemicals (e.g. molecular weight, carbon number, methylene content, branching, hydroxylation, terminal group) are controlled through one of four processes. Initiation controls carbon number and branching. Elongation controls the chain length and incorporation of internal substitutions.

25 Termination determines the class of oleochemical (acid, ester, aldehyde, alcohol, olefin, alkane). 
Modification involves introduction of double bonds, hydroxyl groups, and branching post synthesis of the main alkyl chain. 

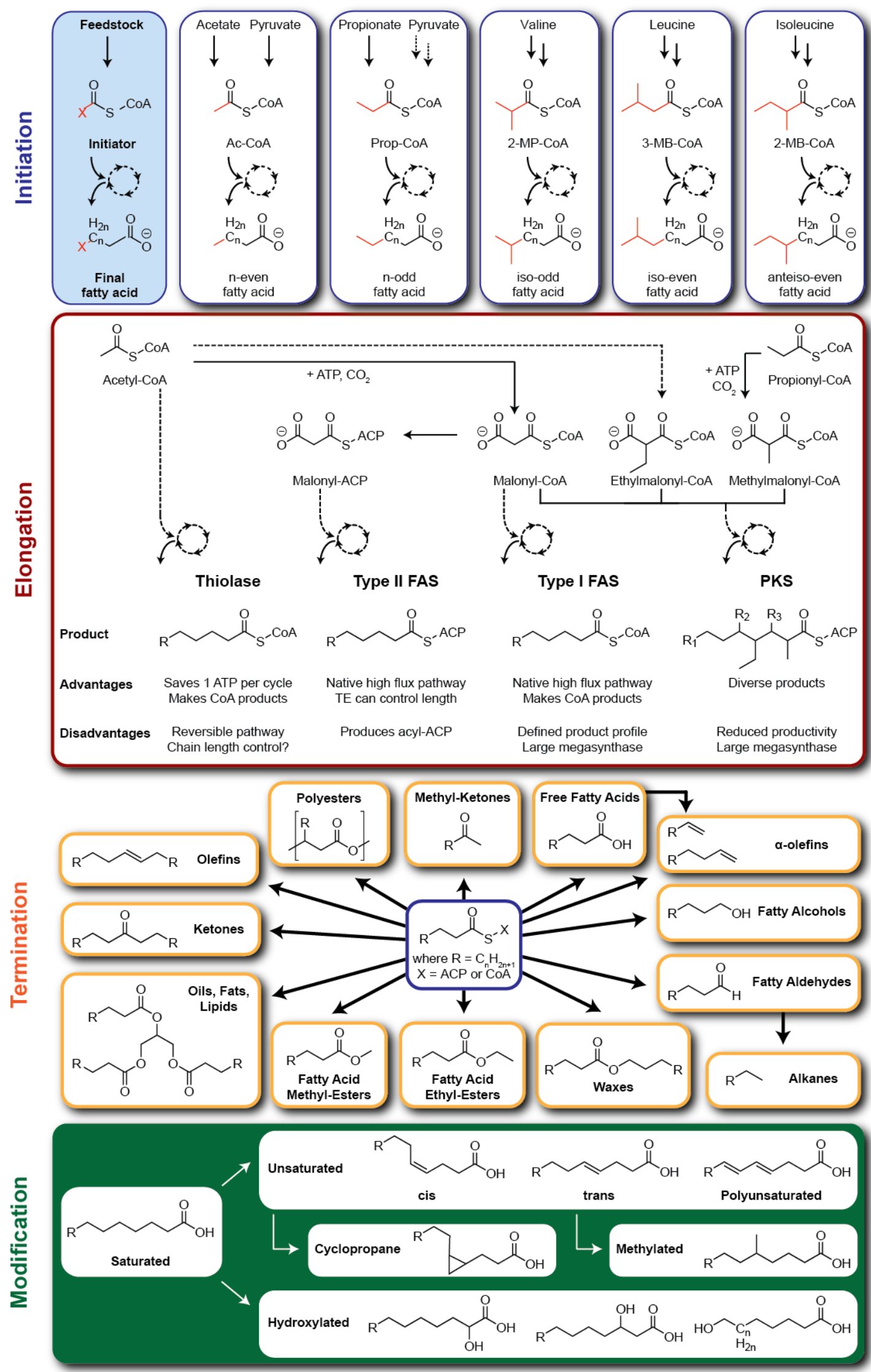


\subsection{Initiation}

Fatty acid synthesis is primed by short acyl-Coenzyme A (acyl-CoA) thioesters. Incorporation of specific primers determines whether the final acyl-chain will be even or odd and whether the chain will be straight or contain branches. For example, in E. coli, even, straight-

5 chain fatty acids are primed by condensation of acetyl-CoA with malonyl-ACP to yield acetoacetyl-ACP, CoA, and $\mathrm{CO}_{2}$. The reaction is catalyzed by $\beta$-ketoacyl-acyl carrier protein synthase III (FabH) (Heath and Rock, 1996). Similarly, odd, straight chain fatty acids are made by $E$. coli when cells are provided with a source of propionyl-CoA, e.g. exogenous propionate or a heterologous propionyl-CoA synthesis pathway (Torella et al., 2013; Tseng and Prather, 2012).

10 Odd chain fatty acids are made because E. coli FabH has activity on propionyl-CoA (Heath and Rock, 1996). Homologs of FabH in other bacteria such as Bacillus subtilis, have activity on a wider range of substrates including branched acyl-CoA (Choi et al., 2000; Kaneda, 1991). When excess valine is fed to cells, it is converted to 2-methyl-propionyl-CoA (2-MP-CoA). Initiation with 2-MP-CoA leads to the formation of iso-branched, odd chain fatty acids (Choi et al., 2000;

15 Howard et al., 2013). Analogously, leucine and isoleucine can be converted to 3-methyl-butyrylCoA (3-MB-CoA) and 2-methyl-butyrl-CoA (2-MB-CoA) leading to the generation of isobranched, even- and anteiso-branched, even-chain fatty acids, respectively (Choi et al., 2000; Howard et al., 2013). Pathways for synthesizing alternative acyl-chains are hypothesized to exist as a means to alter properties of the cell membrane (Kaneda, 1991), but the relationship between

20 membrane composition and function remains poorly understood.

Metabolic engineering strategies that incorporate alternative acyl-chain primers have been used to alter the structure of oleochemical products (Haushalter et al., 2014; Howard et al., 2013). While these initial efforts are promising, several challenges remain. For instance, 
heterologous expression of a promiscuous FabH confers the ability to incorporate alternative primers. In these engineered cells, competition between FabH homologs leads to mixed populations of native (e.g. even, straight chain) and alternative acyl-chains. The mixed population of acyl-chains is incorporated into both the final oleochemical and into membrane

5 lipids. Altering the composition of the membrane may not be desirable because of the impact of composition on membrane function and cell physiology. A second challenge is engineering the cell to efficiently produce the alternative primer from an unrelated carbon source (e.g. glucose). Many groups have succeeded in generating a high selectivity towards alternative acyl-chains by feeding organic acids (Torella et al., 2013; Tseng and Prather, 2012; Wu and San, 2014). Given

10 the high cost of such molecules, the economic viability of these strategies is questionable. Lastly, expression of promiscuous FabH is compatible with the Type II fatty acid biosynthesis pathway found in E. coli and B. subtilis, but it is not known whether alternative elongation pathways (see 3.2) will be able to incorporate alternative primers. In order to leverage the advantages of these pathways, new enzymes will need to be discovered, engineered, and/or

15 evolved.

\subsection{Elongation}

Acyl-chains are made via iterative enzymatic cycles that add two (or more) carbons per cycle. Each cycle is comprised of a Claisen condensation of acyl-thioesters (generating $\beta$-ketoacyl chains) followed by reduction of the $\beta$-keto group (Haapalainen et al., 2006; Heath and

20 Rock, 2002). Elongation cycles can be classified based on four factors (Figure 2) - 1.) type of Claisen condensation (proton extraction vs. decarboxylation), 2.) elongation monomer (acetylCoA, malonyl-CoA, malonyl-ACP, ethyl- or methyl-malonyl-CoA), 3.) whether the enzymes used in the cycle are fused into a single polypeptide (Type I) or are distinct proteins (Type II), 
and 4.) degree to which each $\beta$-carbon is reduced (saturated, unsaturated, $\beta$-hydroxy, $\beta$-keto-). Most fatty acid biosynthesis pathways elongate a growing acyl chain via a decarboxylative Claisen condensation that adds two carbons from a malonyl-(CoA or ACP) thioester donor and fully reduce $\beta$-keto position to a saturated carbon. Most bacteria and yeast mitochondria express

5 a Type II fatty acid biosynthesis pathway that uses distinct enzymes to produce long-chain $\left(\mathrm{C}_{16^{-}}\right.$ $\mathrm{C}_{18}$ ) acyl-ACPs from malonyl-ACP (Heath and Rock, 2002; Tehlivets et al., 2007; Zhang and Rock, 2008). At each stage the intermediates (acyl-ACPs) are accessible to other enzymes. Conversely, eukaryotes typically use a Type I fatty acid synthase that fuses the elongation and reductive enzymes into one protein (Tehlivets et al., 2007). These assembly lines produce 10 predominantly $\mathrm{C}_{16^{-}}$or $\mathrm{C}_{18^{-}}$acyl-CoA using malonyl-CoA as the extension unit. Intermediates are always covalently attached to the fatty acid synthase and passed between enzymatic domains by a flexible phosphopantetheine group attached to acyl-carrier protein domains. The decarboxylative chemistry is irreversible and thereby enables high flux but requires the consumption of one ATP per elongation to produce malonyl-CoA from acetyl-CoA and $\mathrm{CO}_{2}$

15 (catalyzed by acetyl-CoA carboxylase (Polyak et al., 2012)). The extra ATP demand reduces the theoretical oleochemical yield particularly under anaerobic conditions. To overcome this limitation, groups have demonstrated an alternative pathway for producing oleochemicals that uses a reversible thiolase to condense an acyl-CoA with an acetyl-CoA elongation unit (Dellomonaco et al., 2011). The engineered thiolase pathway leverages enzymes used in $\beta$ 20 oxidation (pathway for catabolizing fatty acids) as well as heterologous enzymes (e.g. trans-2enoyl reductase and acetyl-CoA $\mathrm{C}$-acetyltransferase) to create long-chain acyl-CoAs that can be converted to oleochemicals via the reactions described below (see 2.3). Lastly, polyketides, a large class of diverse natural products, are made by the same iterative reaction cycles as fatty 
acids. However, here, the enzymes involved can accept a wider range of elongation units and produce different reductive states at each $\beta$-carbon position in the acyl-chain. The modular nature of polyketide assembly has motivated many groups to engineer hybrid synthases to produce unnatural analogs of known natural products. While significant progress has been made, designer

5 polyketides are not yet commonplace (Cummings et al., 2014; Khosla et al., 2014; Wong and Khosla, 2012).

To date, most published oleochemical production strategies have utilized either the Type I fatty acid synthase in yeast or the Type II fatty acid biosynthesis pathway in bacteria. The Type I FAS produces high flux to a single intermediate, hexadecanoyl-CoA, which can be directly 10 converted to $\mathrm{C}_{16}$ oleochemicals such as ethyl esters (Shi et al., 2014b). In contrast, the discrete enzymology of the Type II pathway allows access to thioesterases for producing free fatty acids of chain lengths other than $\mathrm{C}_{16}$. Individual thioesterases from bacteria and plants have been found to target $\mathrm{C}_{8}-\mathrm{C}_{18}$ acyl-thioesters with differing degrees of specificity (Cantu et al., 2011). However, free fatty acids made by thioesterases must often be activated as CoA-thioesters by 15 acyl-CoA synthetase (e.g. FadD in E. coli) in order to be enzymatically converted into oleochemicals (see 2.3). The ACP to CoA thioester exchange comes with the minimal cost of one ATP per product. Unfortunately, simultaneous thioesterase activity against acyl-CoAs can increase this cost by creating futile cycles of thioester cleavage and formation. The high ATP demand of the thioesterase strategy (for malonyl-CoA and acyl-CoA synthesis) has strongly 20 motivated exploration of the thiolase pathway strategy. However to date, only short chain products (e.g. butanol) and broad product distributions have been achieved (Dellomonaco et al., 2011; Zhuang et al., 2014).

\subsection{Termination}


While the existence of hydrocarbon synthesis in the microbial world has been known for over 45 years (Winters et al., 1969), the enzymatic pathways responsible for producing oleochemicals have mostly been uncovered in the last decade. The biochemistry and engineering of these diverse enzymatic conversions has been detailed in several recent reviews (Huffer et al.,

5 2012; Janßen and Steinbüchel, 2014; Lennen and Pfleger, 2013; Wang and Lu, 2013). Here, termination reactions are defined as those that modify a free fatty acid or acyl-thioester at the carbonyl end through enzymatic reduction, decarboxylation, and/or condensation with other chemicals (Figure 2). In native hosts, most termination reactions act on $\mathrm{C}_{16}$ or $\mathrm{C}_{18}$ acyl-chains, the predominant lengths found in membrane lipids. In vitro, enzymes (e.g. acyl-coA reductase)

10 often show a broader substrate utilization profile (Willis et al., 2011) than the product distribution generated by heterologous expression (Youngquist et al., 2013b), indicating that substrate availability is a determinant of product profile in vivo. When a thioesterase-acyl-CoA synthetase strategy is used to produce medium or short chain acyl-CoAs, expression of a termination pathway leads to a mixture of oleochemical chain lengths coming from both the

15 thioesterase and $\mathrm{C}_{16}$ or $\mathrm{C}_{18}$ acyl-ACPs used to make membrane lipids (Youngquist et al., 2013b). Future efforts to increase product selectivity would benefit from additional in vitro characterization, crystallization, and protein engineering/evolution experiments.

\subsection{Modification}

High levels of saturated fatty acyl chains lead to stiff, tightly packed lipid membranes.

20 Consequently, microbes have evolved methods of modifying acyl-chains (Figure 2) to alter membrane properties in response to stressful conditions (Zhang and Rock, 2008). For example, bacteria are known to increase the percentage of unsaturated fatty acyl-chains at low temperatures to increase fluidity (Mansilla et al., 2004). The location and stereochemistry of the 
double bonds can be varied by expressing desaturases with a desired specificity (Aguilar and de Mendoza, 2006). Microbes also incorporate branched, cyclopropane, and hydroxy fatty acids into membranes (Buist, 2007). The extra carbon in cyclopropane and internally branched fatty acids comes from addition of S-adenosyl-methionine by dedicated synthases across the double

5 bond of an unsaturated phospholipid (Buist, 2007; Grogan and Cronan, JE, 1997). Hydroxylgroups are added all across the acyl-chain $(\alpha-, \beta-, \omega-)$ for incorporation into special lipids (e.g. sphingolipids, lipid A) or extracellular waxes (Cao and Zhang, 2013). While most of these modifying enzymes act on lipids, efforts to biologically produce modified oleochemicals such as $\omega$-hydroxy fatty acids (Lu et al., 2010) and $\beta$-hydroxy fatty acids (Chung et al., 2013) have

10 succeeded.

\section{Successful Metabolic Engineering Strategies:}

For all microbial chemical syntheses, the three main performance metrics are titer, yield, and productivity. Given the hydrophobic nature of oleochemicals, separation from the aqueous broth is simpler than other water soluble products (e.g. ethanol) and product titer is less critical.

15 The important metrics for oleochemical production are therefore productivity and yield. Productivity is important when evaluating natural oil-accumulating organisms such as algae (Griffiths and Harrison, 2009). Lipid productivity by naturally oleaginous (10-20\% DCW lipid), species such as Yarowia lipolytica are on the order of $0.1 \mathrm{~g} / \mathrm{L} / \mathrm{hr}$ (Aggelis and Komaitis, 1999; Papanikolaou and Aggelis, 2002; Tsigie et al., 2011), comparable to the rate of glucose

20 utilization in rapidly growing organisms such as E. coli or Saccharomyces. The theoretical yield of an oleochemical depends on its chain length, any modifications, and the elongation pathway used for its synthesis. Flux balance analysis of genome scale metabolic models is therefore a useful tool for calculating the maximum theoretical yield of chemical products from a given 
feedstock (Caspeta and Nielsen, 2013). For glucose, the most common feedstock, oleochemical yields are typically in the rage of 0.3-0.4 (g oleochemical per g glucose, Figure 3a). Given these yields, the most attractive products are fatty alcohols which sell for 2-3 times the price of free fatty acids and biodiesel (Figure 3). While achieving theoretical yield of secreted oleochemicals remains challenging for many products, significant progress has been made by applying a small set of metabolic engineering strategies to produce alkanes (Schirmer et al., 2010), ethyl esters (Steen et al., 2010), fatty alcohols (Youngquist et al., 2013b), acetate esters (Rodriguez et al., 2014), methyl ketones (Goh et al., 2014), and polyhydroxyalkanoates (Agnew et al., 2012) in $E$. coli. Similar metabolic engineering strategies have been applied to increase oleochemical

10 productivity in naturally high-yielding oleaginous microbes (Blazeck et al., 2014; Tai and Stephanopoulos, 2013; Wältermann et al., 2005). In general, production of an oleochemical is optimized by blocking competing pathways that consume products and intermediates, maximizing activity of the oleochemical synthesis pathway, and balancing the synthesis of precursors, intermediates and co-factors (Figure 4).

\begin{tabular}{|c|c|c|c|c|c|c|c|c|c|c|c|c|}
\hline \multirow{4}{*}{ 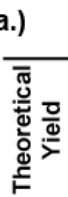 } & \multirow{4}{*}{$\begin{array}{r}\text { Class } \\
\text { Acyl-Chain } \\
\mathrm{mol} / \mathrm{mol} \\
\mathrm{g} / \mathrm{g}\end{array}$} & \multirow{2}{*}{$\begin{array}{c}\text { FAME } \\
\text { C16 }\end{array}$} & \multirow{2}{*}{$\begin{array}{c}\text { FAEE } \\
\text { C16 }\end{array}$} & \multirow{2}{*}{$\frac{\text { AAcE }}{\mathrm{C} 16}$} & \multirow{2}{*}{$\frac{\text { Alkane }}{\text { C15 }}$} & \multirow{2}{*}{$\frac{\text { Methyl-Ketone }}{\text { C14 }}$} & \multicolumn{3}{|c|}{ Free Fatty Acid } & \multicolumn{3}{|c|}{ Fatty Alcohol } \\
\hline & & & & & & & C8 & C12 & C16 & C8 & C12 & C16 \\
\hline & & 0.203 & 0.231 & 0.231 & 0.250 & 0.273 & 0.545 & 0.353 & 0.261 & 0.500 & 0.333 & 0.250 \\
\hline & & 0.305 & 0.364 & 0.364 & 0.295 & 0.343 & 0.437 & 0.392 & 0.371 & 0.361 & 0.345 & 0.336 \\
\hline Jan & & & & esel: & & & $\mathrm{n} / \mathrm{a}$ & n/a & $\$ 0.71$ & $\$ 1.66$ & $\$ 0.79$ & $\$ 0.79$ \\
\hline
\end{tabular}

b.)

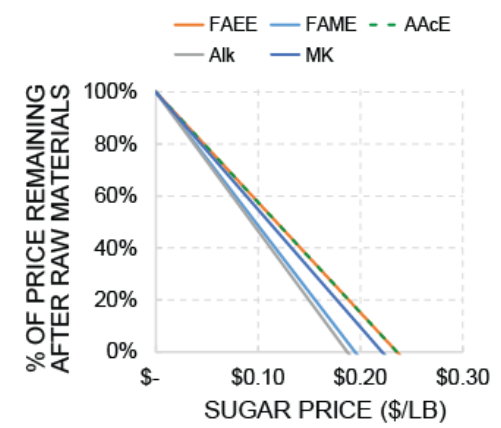

c.)

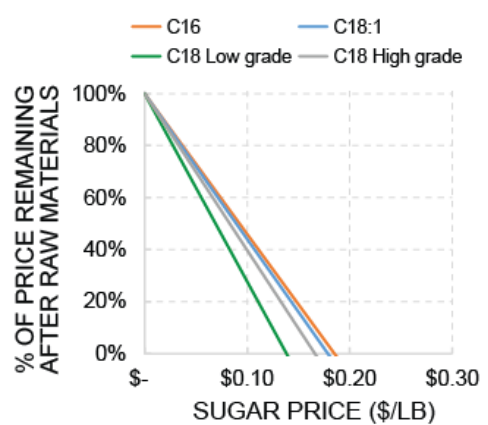

d.)

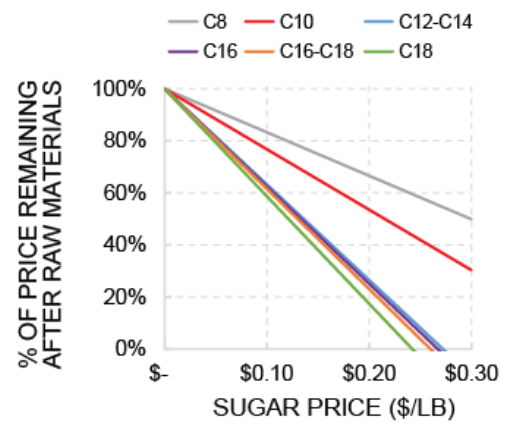


Figure 3. Oleochemical economics. a.) The maximum theoretical yield of each oleochemical from glucose was calculated by performing flux balance analysis on a modified version of an E. coli genome scale metabolic model (iJO1366 (Orth et al., 2011) supplemented with reactions comprising the thiolase pathway and the rage of termination reactions described in 3.4). Oleochemical selling prices were obtained from January 29, 2014 pricing reports provided by ISIS. b.-d.) The impact of sugar price on process economics was demonstrated by plotting the gross margin based on only feedstock costs. The Y-axis was calculated by subtracting the cost of glucose needed to make $1 \mathrm{lb}$ of oleochemical from the oleochemical selling price and dividing it by the oleochemical selling price. Average theoretical yields were used for products containing multiple species. Abbreviations: FAEE - fatty acid ethyl ester; FAME - fatty acid methyl ester; AAce - acetate acyl ester; Alk - alkane; MK - methyl-ketone.

a. General Metabolic Engineeirng Strategy

1. Block competing pathways and futile cycles

2. Provide strong, irreversible pull toward desired product

3. Deregulate fatty acid biosynthesis

4. Balance co-factors, reducing power, and enzyme activity

5. Push carbon flux into acetyl-CoA and fatty acid biosynthesis

6. Remove or sequester products to avoid toxicity

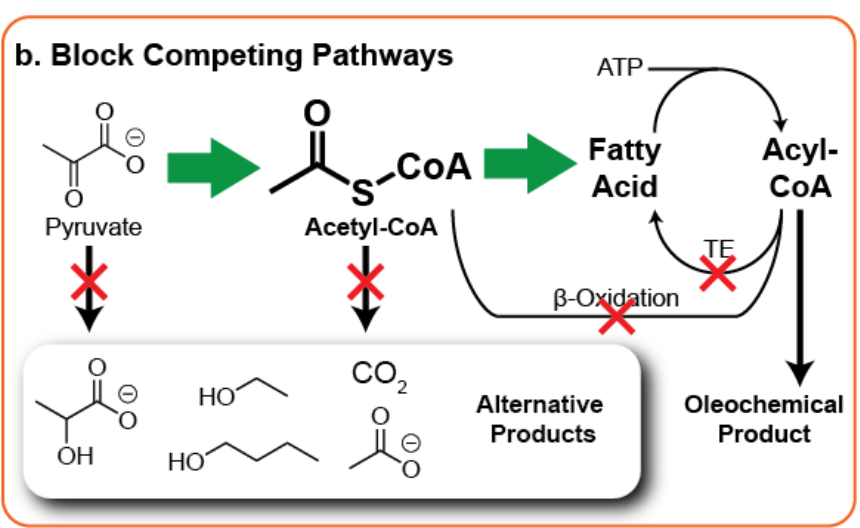

c. Transiently Express Essential Enzymes

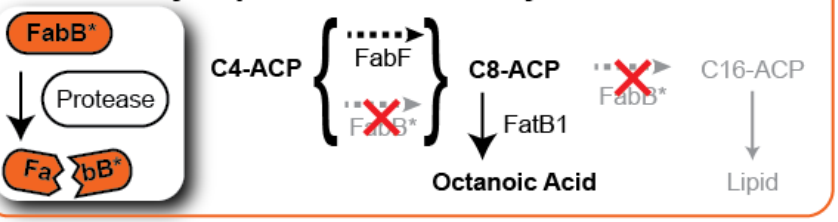

d. Dergulate Fatty Acid Biosynthesis and Maximize Pathway Activity

\section{e. Optimize Enzyme Expression or Activity}

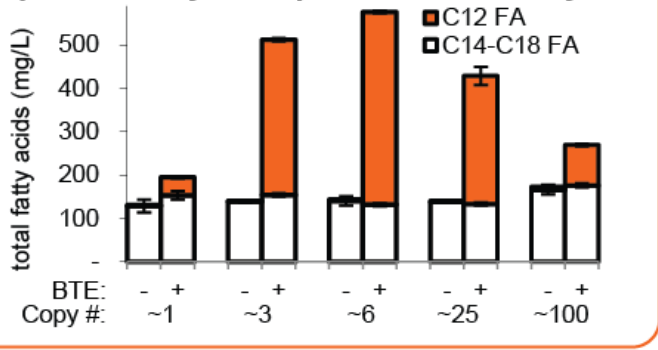

f. Balance Co-Factor Synthesis
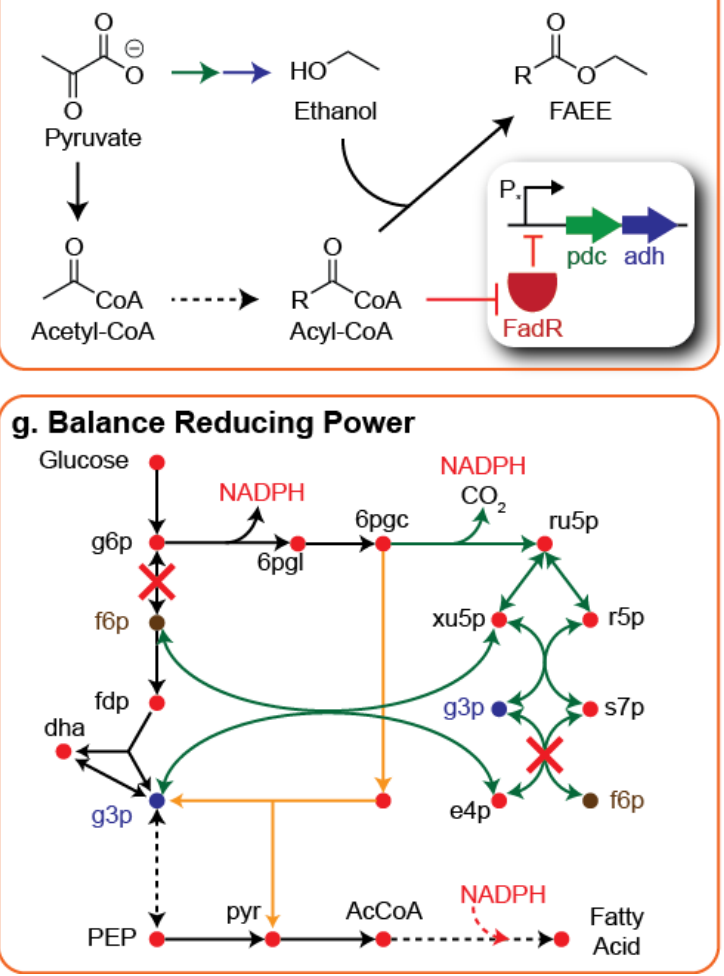
Figure 4. Successful Metabolic Engineering Strategies. a). List of general strategies. b.) Gene deletions and c.) transient removal of enzymes can be used to block flux from unwanted pathways. d.) In E. coli, deregulation is accomplished by expression of a thioesterase which shunts flux away from long-chain acyl-ACP, the key regulatory signal. e.) Maximal production of oleochemicals often requires optimized, not maximal, expression of rate limiting enzymes (titration of a thioesterase is shown). f.) Dynamic control strategies such as using FadR to sense acyl-CoA levels have been used to balance the synthesis of individual co-substrates. g.) Genome scale metabolic models have been used to identify global strategies for balancing co-factor utilization and maximizing flux to desired oleochemicals.

\subsection{Block competing pathways}

The simplest strategy for directing flux through metabolism is to block entrance into undesired pathways. Blocking flux is often accomplished by deleting all genes that encode enzymes at specific branch points in metabolism. In the case of oleochemicals, competing pathways include $\beta$-oxidation, central metabolic pathways that compete with the synthesis of acetyl-CoA, and pathways that consume acetyl-CoA (Figure $\mathbf{4 b}$ ). Product consumption is often

15 blocked by preventing flux into $\beta$-oxidation (e.g. deleting acyl-CoA synthetases (Chen et al., 2014)) or by removing all isozymes for an oxidative step in the cyclic pathway (Agnew et al., 2012; Valle-Rodríguez et al., 2014). Strategies for blocking product consumption are product specific since acyl-CoA synthetase and many $\beta$-oxidation enzymes are frequently involved in synthesizing essential acyl-CoA intermediates. For example, PHA and methyl-ketone pathways

20 require $\beta$-oxidation enzymes to produce penultimate intermediates, 3-hydroxy- and 3-keto-acylCoAs respectively.

Regardless of feedstock, oleochemical pathways begin with acetyl-CoA, a central metabolic intermediate primarily made from pyruvate and otherwise consumed for energy generation (TCA cycle, acetate secretion) and biosynthesis (amino acid and lipid). In bacteria, 
deletion of acetate formation and other fermentation pathways has a positive impact on acetylCoA levels and production of products made from acetyl-coA (Goh et al., 2014; Zha et al., 2009). Analogously, strategies that improved availability of cytosolic acetyl-CoA in yeast enhanced production of acetyl-CoA derived products such as $\alpha$-santalene (Chen et al., 2013),

5 butanol (Krivoruchko et al., 2013), polyhydroxybutyrate (Kocharin et al., 2012) and fatty acid ethyl esters (de Jong et al., 2014). Strategies for increasing cytosolic acetyl-CoA pool in $S$. cerevisiae include increasing activity of acetyl-CoA synthetase and/or increasing availability of its substrate, acetate. For example, overexpression of acetyl-CoA synthetases ACS1 and ACS2 resulted in an increase of intracellular acetyl-CoA by two-fold and five-fold, respectively (Chen

10 et al., 2010). Acetate pools were increased by overexpression of alcohol dehydrogenase, $A D H 2$, and acetaldehyde dehydrogenase, ALD6, which catalyze the conversion of ethanol to acetaldehyde to acetate. Similarly, combined overexpression of a mutant acetyl-CoA synthetase, AcsSE P641L (prevents regulation by acetylation), from Salmonella enterica and ALD6 increased acetyl-CoA synthethase activity by four-fold (Shiba et al., 2007). In many cases, competing pathways encode essential enzymes or enzymes whose deletion causes a severe phenotype (e.g. auxotrophy or reduced energy generation). For this reason, strategies that transiently control gene expression and block unwanted enzyme activity without gene deletion are advantageous. For example, deletion of genes in the TCA cycle is predicted to improve flux towards fatty acids and other malonyl-CoA derived products

20 (Ranganathan et al., 2012; Xu et al., 2011) but comes with the trade-off of reduced energy generation and reduced rate and yield of aerobic biomass generation. Alternatively, the use of toggle switches to transiently control transcription of gltA and thereby flux into the TCA cycle increased production of isobutanol and other acetyl-CoA derived biofuels more than three-fold in 
E. coli (Soma et al., 2014). A similar transient strategy was used to control expression of fatty acid synthases in E. coli and thereby increase flux to octanoic acid (Figure 4c) (Torella et al., 2013). Here, $f a b B$, which encodes the fatty acid synthase required for elongation beyond $\mathrm{C} 8$ was replaced with a variant fused to a protease tag. When the protease was transiently expressed,

5 FabB* $^{*}$ was degraded preventing elongation of medium chain acyl-ACPs and elevating levels of octanoyl-ACP, the substrate of a heterologously expressed $\mathrm{C}_{8}$-thioesterase. When combined with a FabF variant incapable of elongating beyond $\mathrm{C}_{8}$, a $30 \%$ increase in free fatty acid titer was observed.

\subsection{Deregulate Fatty Acid Biosynthesis and Maximize Pathway Activity}

Fatty acid biosynthesis is energetically expensive and therefore a tightly regulated process within microorganisms. Strategies that eliminate or by-pass regulation have been highly successful in increasing production of oleochemicals. In E. coli, the major regulatory mode is feedback inhibition of biosynthetic enzymes by long-chain acyl-ACPs (Fujita et al., 2007; Lennen and Pfleger, 2012). Thioesterases hydrolyze acyl-chains from ACP (creating a pool of

15 free fatty acids) and thereby reduce the availability of long-chain acyl-ACPs (Figure 4d). Depletion of the regulatory signal removes feedback inhibition and leads to elevated flux through the pathway (Davis et al., 2000; Lennen et al., 2010; Lu et al., 2008; Voelker and Davies, 1994). The elevated flux is distributed into two pools: long-chain acyl-ACPs that are incorporated into phospholipids and free fatty acids generated by thioesterase activity. The dual advantages of

20 thioesterase expression - providing a product sink and depleting a key regulatory signal - make it an attractive strategy for increasing flux towards oleochemicals. However, to leverage this strategy for producing other oleochemicals, the rate of free fatty acid synthesis (thioesterase activity) must be balanced with downstream pathway flux. 
The thioesterase strategy works well in E. coli, but has not been as effective in other organisms (e.g. cyanobacteria (Liu et al., 2011; Ruffing, 2014, 2013)). This may be due to differences in the way fatty acid biosynthesis is regulated in these organisms. Many organisms use transcriptional regulation to modulate the level of fatty acid biosynthetic enzymes (My et al.,

5 2013; Zhang and Rock, 2009). Several regulators (e.g. FadR-acyl-CoA, FapR-malonyl-CoA) respond to metabolites involved in the pathway. In some cases, overexpression of regulatory proteins leads to improved flux by increasing the levels of fatty acid biosynthetic enzymes. For example, overexpression of FadR in E. coli leads to increased levels of FabB, FabF, FabH, FabI, and $\mathrm{Acc} \mathrm{AD}$ as well as elevated free fatty acid titers (achieving the highest reported yields to

10 date). This strategy was also used to increase production of methyl ketones (Goh et al., 2014). Knowledge of how fatty acid metabolism is regulated remains a barrier to designing oleochemical production strategies in non-model organisms.

In many organisms the production of malonyl-CoA by acetyl-CoA carboxylase (ACCase) is known to be a rate-limiting step in fatty acid biosynthesis. Interestingly, overexpression of 15 ACCase has had mixed success. In E. coli, overexpression of the four native ACC genes resulted in a six-fold increase in rate of fatty acid biosynthesis (Davis et al., 2000; Liu et al., 2010). In Y. lipolytica, overexpression of endogenous ACC1 increased lipid content twofold from $8.8 \%$ to $17.9 \%$ (Tai and Stephanopoulos, 2013). In S. cerevisiae, plasmid-based overexpression of endogenous $A C C 1$ increased lipid content by $58 \%$, from $4.3 \%$ to $6.8 \%$

20 (Runguphan and Keasling, 2014). A different study failed to show an increase in fatty acid content when overexpressing $A C C 1$ from a plasmid (Shi et al., 2014a). In S. cerevisiae, activity of Acc1p is inactivated upon phosphorylation by the kinase Snf1p. Cells expressing ACC1 mutants that cannot be inactivated by phosphorylation show increased lipid content (Hofbauer et 
al., 2014; Shi et al., 2014a). These mixed results highlight the importance of understanding regulatory mechanisms of fatty acid synthesis when designing metabolic engineering strategies.

\subsection{Optimize Enzyme Expression Level and/or Activity}

A central tenant in metabolic engineering is the need to balance gene expression in order

5 to provide sufficient enzymatic activity but not waste resources on excess protein synthesis. Synthetic biology approaches have enabled facile titration of gene expression through variation of DNA copy number, promoter strength, induction, and translation initiation rate. Often, the optimal level of oleochemical synthesis is associated with an intermediate value of one of these parameters, with deviations leading to decreased production and cell fitness. For example, titration of thioesterase activity by copy number (Lennen et al., 2010) or induction (Hoover et al., 2011) increased free fatty acid titer up to a medium level. Beyond this level, sharp decreases in titer and cellular fitness were observed (Figure 4e). Similarly, an intermediate level of acyl-CoA synthetase expression generated by replacing the native $\mathrm{P}_{f a d D}$ promoter with a stronger $\mathrm{P}_{\text {TRC }}$ promoter (45-fold increase in mRNA) resulted in a higher rate of dodecanoic acid conversion to

15 dodecanol than either the base strain or plasmid based expression (1000-fold increase in mRNA relative to base) (Youngquist et al., 2013b). Optimization of static regulation can be timeconsuming and expensive if facile screens are not available. Alternatively, regulation linked to the presence of key intermediates can be used to dynamically alter expression of pathway enzymes to increase consumption or production of the intermediate. For example, engineered

20 FadR-responsive promoters were engineered to up- or down-regulate expression in response to acyl-CoA levels. When these promoters were used to regulate expression of acyl-CoA synthetase, ethanol synthesis, and wax-ester synthetase (Figure 4f), biodiesel production was increased three-fold, achieving the highest reported yield (Zhang et al., 2012a). Similar efforts 
using promoters engineered to respond to FapR, a dynamic regulatory protein that responds to malonyl-CoA levels, was used to increase free fatty acid titer 3-fold (Xu et al., 2014). Unfortunately, dynamic regulatory proteins are not available for all intermediates in oleochemical pathways. To circumvent this challenge, functional genomics studies were used to

5 identify promoters that were upregulated or downregulated in response to elevated levels of HMG-CoA in E. coli. When used to regulate expression of HMG-CoA synthase and HMG-CoA reductase, flux through the mevalonate pathway was increased 2-fold (Dahl et al., 2013). As more is learned about regulation of fatty acid and oleochemical pathways, additional opportunities to optimize enzyme activity will emerge.

\subsection{Balance Co-Factor Generation and Utilization}

Reducing power required for synthesis of many intracellular metabolites is often provided in the form of NADPH, and in the case of oleochemicals, NADPH is required in each elongation cycle and frequently in terminal reductions to convert acids into aldehydes, alcohols, olefins, and alkanes. The NADPH requirement is problematic because catabolic pathways

15 typically generate excess $\mathrm{NADH}$ as electron carriers. Three strategies have been used to correct this imbalance. Genome scale metabolic models and gene-deletion algorithms were used to identify mutations in glycolysis and the pentose-phosphate pathway that would force carbon flux from glucose through the Entner-Dodouroff pathway (Figure 4g) and generate NADPH needed for fatty acid synthesis (Ranganathan et al., 2012; Xu et al., 2011). Instead of balancing NADPH

20 supply, NADH-utilizing FabG homologs were expressed in E. coli resulting in modest improvements in free fatty acid and methyl ketone production under anaerobic conditions (Javidpour et al., 2014). The synthetic thiolase pathway discussed above (Dellomonaco et al., 2011) uses reductive enzymes that favor NADH and therefore by-passes any redox imbalance. 
Going forward, balancing co-factor generation and consumption will be a critical step for maximizing oleochemical production under anaerobic conditions.

\section{Future Directions:}

Significant progress has been made in engineering microbes to produce free fatty acids,

5 and lipids in high yield reaching 73\% (Zhang et al., 2012b) and 63\% (Blazeck et al., 2014) of the theoretical yield in the best literature reports. Reported yields of other oleochemicals are typically lower, but a few are approaching $50 \%$ of the theoretical maximum. Further improvements are likely to come from optimizing advanced cultivation strategies, reducing stresses (Lennen et al., 2011; Liu et al., 2013; Royce et al., 2013) and elevated maintenance energy requirements (Youngquist et al., 2013a) caused by oleochemical production, improving the inherent catalytic rates of oleochemical producing enzymes, and improving product sequestration/secretion (Figure 5). Many of these strategies will require improvements in the enzymes that make up an oleochemical pathway. There are several tools available for enzyme design and engineering, including directed evolution, rational design, or computational methods

15 (Damborsky and Brezovsky, 2014; Eriksen et al., 2014; Zanghellini, 2014). These methods have been used to successfully improve the production of other biofuels and metabolic products (Atsumi and Liao, 2008) and are likely to lead to improvements in oleochemical production. Similarly, protein engineering efforts that remove allosteric regulation, alter the substrate specificity, and/or alter the cofactor requirements of oleochemical producing enzymes (Figure 5)

20 will enable researchers to develop high-yielding pathways for producing the wide range of oleochemical products found in nature.

Another potential target for improving microbial oleochemical production is improved secretion or intracellular storage of oleochemicals. In contrast to fatty acids, the neutral storage 
lipids triacylglycerides and steryl esters do not show lipotoxicity. It has been shown that yeast cells with a deletion of the diacylglycerol acyltransferase DGAl or acyl CoA:sterol acyltransferase ARE2 are more susceptible to liponecrotic death induced by palmitoleic acid (Sheibani et al., 2014). Neutral storage lipids are stored in specialized organelles called lipid 5 droplets. This compartmentalization provides a strong pull for TAG synthesis, by removing the product from the equilibrium. Intracellular storage of triacylglycerides can be increased by overexpression of enzymes that show diacylglycerol-acyltransferase activity (e.g. DGAl). By knocking out enzymes that control the reverse reaction, levels of intracellular storage can also be increased. Deletion of triacylglyceride lipases TGL3, TGL4 and TGL5 in Saccharomyces

10 cerevisiae increased triacylglyceride levels by 3 -fold (Athenstaedt and Daum, 2005).

A similar effect can be achieved if oleochemical can be secreted and removed from culture. For example, co-culturing a fatty alcohol producing E. coli in dodecane increased the percentage of extracellular product from $40 \%$ to near $100 \%$ and increased product yield (Youngquist et al., 2013b). Metabolite secretion circumvents toxicity caused by elevated product

15 levels in the cytoplasm, periplasm, and/or membrane, depletes product inhibition signals, and prevents reverse pathway flux where terminal steps are reversible (i.e. fatty alcohols). Thus far, secretion of oleochemical products has relied on exporters native to the selected host. Altering the expression of native and/or heterologous transporters could potentially enhance secretion. For example, introduction of efflux pumps increased the tolerance of E. coli to several aliphatic

20 biofuels and increased production of isopentenol (Dunlop et al., 2011; Foo et al., 2014). Pumps capable of secreting free fatty acids have been identified (Lennen et al., 2013) but further work is needed to identify pumps for other oleochemicals. 


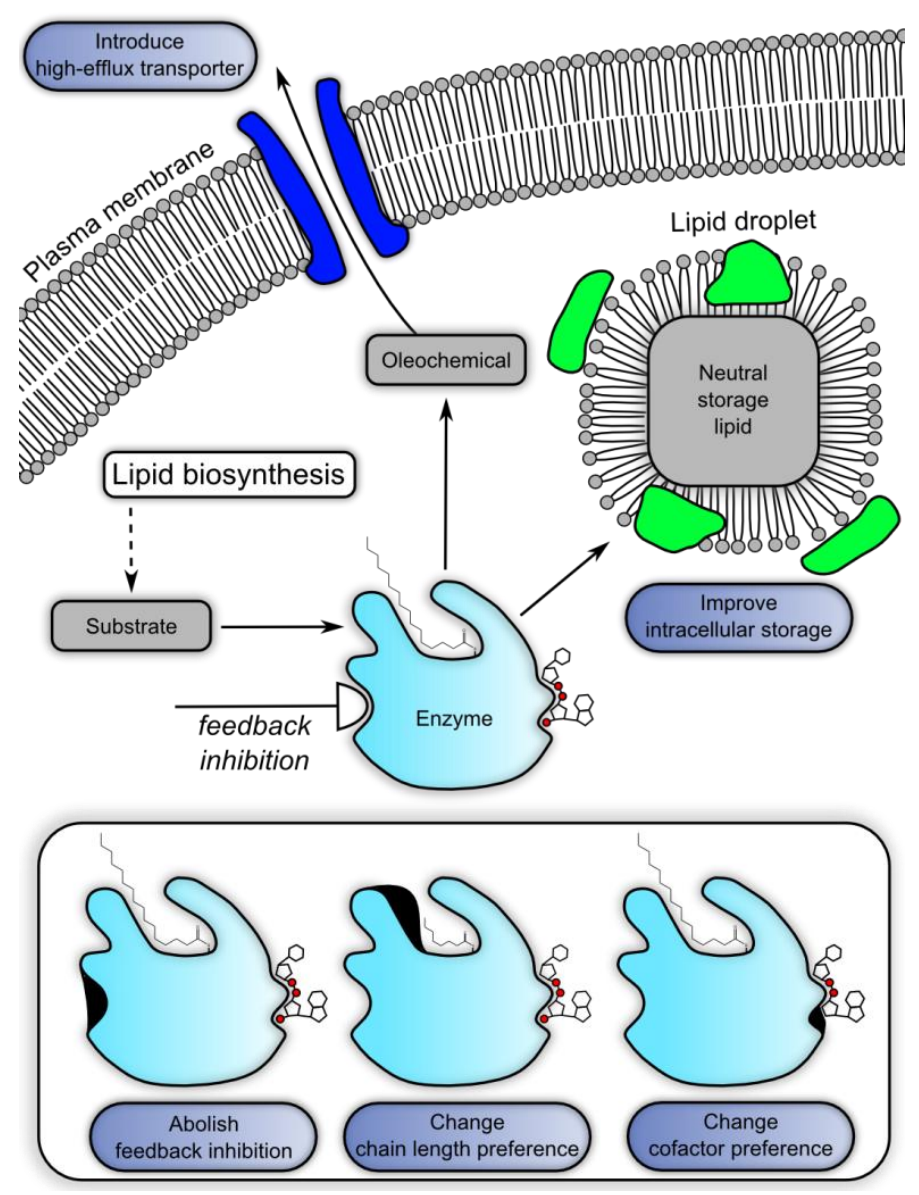

Figure 5. Current challenges in microbial oleochemical production. Economically viable production of oleochemicals in engineered microbes will require improvement of several critical aspects, e.g. abolishing feedback inhibition, optimizing substrate specificity by changing chain-

5 length preference, balancing redox balance by changing cofactor preference, improving intracellular storage and/or introducing high-efflux transporters for efficient secretion of the final product.

\section{Conclusion}

Metabolic engineering has the potential to generate biocatalysts for harnessing the wide range of oleochemicals that can be produced via fatty acid metabolism. Tremendous progress has been made in the last decade in identifying enzymes, optimizing their function, and demonstrating successful metabolic engineering strategies in both E. coli and yeast. High yields 
have been achieved for a few oleochemicals and set the stage for optimization of other targets. Unlocking the full potential of microbial oleochemical production will require combined use of known strategies and development of superior enzymes. Optimized pathways with improved enzymes will allow for highly efficient cell factories and also diversify the range of products that 5 can be obtained by microbial production.

\section{Acknowledgements}

The collaboration that led to the composition of this review was supported by the National Science Foundation (CBET-1149678) and the European Research Council (No. 247013). 


\section{References}

Aggelis, G., Komaitis, M., 1999. Enhancement of single cell oil production by Yarrowia lipolytica growing in the presence of Teucrium polium L. aqueous extract. Biotechnol. Lett. 21, 747-749. doi:10.1023/A:1005591127592

5 Agnew, D.E., Stevermer, A.K., Youngquist, J.T., Pfleger, B.F., 2012. Engineering Escherichia coli for production of C12-C14 polyhydroxyalkanoate from glucose. Metab. Eng. 14, 705713. doi:10.1016/j.ymben.2012.08.003

Aguilar, P.S., de Mendoza, D., 2006. Control of fatty acid desaturation: a mechanism conserved from bacteria to humans. Mol. Microbiol. 62, 1507-14. doi:10.1111/j.13652958.2006.05484.x

Athenstaedt, K., Daum, G., 2005. Tg14p and Tg15p, two triacylglycerol lipases of the yeast Saccharomyces cerevisiae are localized to lipid particles. J. Biol. Chem. 280, 37301-37309. doi:10.1074/jbc.M507261200

Atsumi, S., Liao, J.C., 2008. Directed evolution of Methanococcus jannaschii citramalate synthase for biosynthesis of 1-propanol and 1-butanol by Escherichia coli. Appl. Environ. Microbiol. 74, 7802-7808. doi:10.1128/AEM.02046-08

Biermann, U., Bornscheuer, U., Meier, M.A.R., Metzger, J.O., Schäfer, H.J., 2011. Oils and fats as renewable raw materials in chemistry. Angew. Chem. Int. Ed. Engl. 50, 3854-71. doi:10.1002/anie.201002767

20 Blazeck, J., Hill, A., Liu, L., Knight, R., Miller, J., Pan, A., Otoupal, P., Alper, H.S., 2014. Harnessing Yarrowia lipolytica lipogenesis to create a platform for lipid and biofuel production. Nat. Commun. 5, 3131. doi:10.1038/ncomms4131 
Buist, P.H., 2007. Exotic biomodification of fatty acids. Nat. Prod. Rep. 24, 1110-27. doi:10.1039/b508584p

Cantu, D.C., Chen, Y., Lemons, M.L., Reilly, P.J., 2011. ThYme: a database for thioester-active enzymes. Nucleic Acids Res. 39, D342-6. doi:10.1093/nar/gkq1072

5 Cao, Y., Zhang, X., 2013. Production of long-chain hydroxy fatty acids by microbial conversion. Appl. Microbiol. Biotechnol. 97, 3323-31. doi:10.1007/s00253-013-4815-z

Caspeta, L., Nielsen, J., 2013. Economic and environmental impacts of microbial biodiesel. Nat. Biotechnol. 31, 789-93. doi:10.1038/nbt.2683

Chan, D.I., Vogel, H.J., 2010. Current understanding of fatty acid biosynthesis and the acyl carrier protein. Biochem. J 430, 1-19. doi:doi:10.1042/BJ20100462

Chen, F., Zhou, J., Shi, Z., Liu, L., Du, G., Chen, J., 2010. [Effect of acetyl-CoA synthase gene overexpression on physiological function of Saccharomyces cerevisiae]. Wei Sheng Wu Xue Bao 50, 1172-1179.

Chen, L., Zhang, J., Lee, J., Chen, W.N., 2014. Enhancement of free fatty acid production in

15 Saccharomyces cerevisiae by control of fatty acyl-CoA metabolism. Appl. Microbiol. Biotechnol. 98, 6739-50. doi:10.1007/s00253-014-5758-8

Chen, Y., Daviet, L., Schalk, M., Siewers, V., Nielsen, J., 2013. Establishing a platform cell factory through engineering of yeast acetyl-CoA metabolism. Metab. Eng. 15, 48-54. doi:10.1016/j.ymben.2012.11.002

20 Choi, K.-H., Heath, R.J., Rock, C.O., 2000. beta -Ketoacyl-Acyl Carrier Protein Synthase III (FabH) Is a Determining Factor in Branched-Chain Fatty Acid Biosynthesis. J. Bacteriol. 182, 365-370. doi:10.1128/JB.182.2.365-370.2000 
Chung, A.-L., Zeng, G.-D., Jin, H.-L., Wu, Q., Chen, J.-C., Chen, G.-Q., 2013. Production of medium-chain-length 3-hydroxyalkanoic acids by $\beta$-oxidation and phaC operon deleted Pseudomonas entomophila harboring thioesterase gene. Metab. Eng. 17, 23-9. doi:10.1016/j.ymben.2013.02.001

5 Cummings, M., Breitling, R., Takano, E., 2014. Steps towards the synthetic biology of polyketide biosynthesis. FEMS Microbiol. Lett. 351, 116-25. doi:10.1111/15746968.12365

Dahl, R.H., Zhang, F., Alonso-Gutierrez, J., Baidoo, E., Batth, T.S., Redding-Johanson, A.M., Petzold, C.J., Mukhopadhyay, A., Lee, T.S., Adams, P.D., Keasling, J.D., 2013. 10 Engineering dynamic pathway regulation using stress-response promoters. Nat. Biotechnol. 31, 1039-46. doi:10.1038/nbt.2689

Damborsky, J., Brezovsky, J., 2014. Computational tools for designing and engineering enzymes. Curr. Opin. Chem. Biol. 19, 8-16. doi:10.1016/j.cbpa.2013.12.003

Davis, M.S., Solbiati, J., Cronan, J.E., 2000. Overproduction of acetyl-CoA carboxylase activity increases the rate of fatty acid biosynthesis in Escherichia coli. J. Biol. Chem. 275, 285938. doi:10.1074/jbc.M004756200

De Jong, B.W., Shi, S., Siewers, V., Nielsen, J., 2014. Improved production of fatty acid ethyl esters in Saccharomyces cerevisiae through up-regulation of the ethanol degradation pathway and expression of the heterologous phosphoketolase pathway. Microb. Cell Fact. 13, 39. doi:10.1186/1475-2859-13-39

Dellomonaco, C., Clomburg, J.M., Miller, E.N., Gonzalez, R., 2011. Engineered reversal of the $\beta$-oxidation cycle for the synthesis of fuels and chemicals. Nature 476, 355-9. doi:10.1038/nature10333 
Dunlop, M.J., Dossani, Z.Y., Szmidt, H.L., Chu, H.C., Lee, T.S., Keasling, J.D., Hadi, M.Z., Mukhopadhyay, A., 2011. Engineering microbial biofuel tolerance and export using efflux pumps. Mol. Syst. Biol. 7, 487. doi:10.1038/msb.2011.21

Eriksen, D.T., Lian, J., Zhao, H., 2014. Protein design for pathway engineering. J. Struct. Biol. 185, 234-242. doi:10.1016/j.jsb.2013.03.011

Fargione, J., Hill, J., Tilman, D., Polasky, S., Hawthorne, P., 2008. Land clearing and the biofuel carbon debt. Science 319, 1235-8. doi:10.1126/science.1152747

Foo, J.L., Jensen, H.M., Dahl, R.H., 2014. Improving Microbial Biogasoline Production in Escherichia coli Using. doi:10.1128/mBio.01932-14.Updated

10 Fujita, Y., Matsuoka, H., Hirooka, K., 2007. Regulation of fatty acid metabolism in bacteria. Mol. Microbiol. 66, 829-39. doi:10.1111/j.1365-2958.2007.05947.x

Goh, E.-B., Baidoo, E.E.K., Burd, H., Lee, T.S., Keasling, J.D., Beller, H.R., 2014. Substantial improvements in methyl ketone production in E. coli and insights on the pathway from in vitro studies. Metab. Eng. 26, 67-76. doi:10.1016/j.ymben.2014.09.003

15 Griffiths, M.J., Harrison, S.T.L., 2009. Lipid productivity as a key characteristic for choosing algal species for biodiesel production. J. Appl. Phycol. 21, 493-507. doi:10.1007/s10811008-9392-7

Grogan, D., Cronan, JE, J., 1997. Cyclopropane ring formation in membrane lipids of bacteria. Microbiol. Mol. Biol. Rev. 61, 429-441.

20 Haapalainen, A.M., Meriläinen, G., Wierenga, R.K., 2006. The thiolase superfamily: condensing enzymes with diverse reaction specificities. Trends Biochem. Sci. 31, 64-71. doi:10.1016/j.tibs.2005.11.011 
Haushalter, R.W., Kim, W., Chavkin, T. a, The, L., Garber, M.E., Nhan, M., Petzold, C.J., Katz, L., Keasling, J.D., 2014. Production of anteiso-branched fatty acids in Escherichia coli; next generation biofuels with improved cold-flow properties. Metab. Eng. 26, 111-118. doi:10.1016/j.ymben.2014.09.002

Heath, R.J., Rock, C.O., 1996. Inhibition of beta-Ketoacyl-Acyl Carrier Protein Synthase III (FabH) by Acyl-Acyl Carrier Protein in Escherichia coli. J. Biol. Chem. 271, 10996-11000. doi:10.1074/jbc.271.18.10996

Heath, R.J., Rock, C.O., 2002. The Claisen condensation in biology. Nat. Prod. Rep. 19, 581596. doi:10.1039/b110221b

Hofbauer, H.F., Schopf, F.H., Schleifer, H., Knittelfelder, O.L., Pieber, B., Rechberger, G.N., Wolinski, H., Gaspar, M.L., Kappe, C.O., Stadlmann, J., Mechtler, K., Zenz, A., Lohner, K., Tehlivets, O., Henry, S. a, Kohlwein, S.D., 2014. Regulation of gene expression through a transcriptional repressor that senses acyl-chain length in membrane phospholipids. Dev. Cell 29, 729-39. doi:10.1016/j.devcel.2014.04.025

15 Hoover, S.W., Marner, W.D., Brownson, A.K., Lennen, R.M., Wittkopp, T.M., Yoshitani, J., Zulkifly, S., Graham, L.E., Chaston, S.D., McMahon, K.D., Pfleger, B.F., Marner II, W.D., others, 2011. Bacterial production of free fatty acids from freshwater macroalgal cellulose. Appl. Microbiol. Biotechnol. 91, 435-446. doi:10.1007/s00253-011-3344-X

Howard, T.P., Middelhaufe, S., Moore, K., Edner, C., Kolak, D.M., Taylor, G.N., Parker, D.A.,

Lee, R., Smirnoff, N., Aves, S.J., Love, J., 2013. Synthesis of customized petroleum-replica fuel molecules by targeted modification of free fatty acid pools in Escherichia coli. Proc. Natl. Acad. Sci. U. S. A. 110, 7636-41. doi:10.1073/pnas.1215966110 
Huffer, S., Roche, C.M., Blanch, H.W., Clark, D.S., 2012. Escherichia coli for biofuel production: bridging the gap from promise to practice. Trends Biotechnol. 30, 538-45. doi:10.1016/j.tibtech.2012.07.002

Janßen, H.J., Steinbüchel, A., 2014. Fatty acid synthesis in Escherichia coli and its applications towards the production of fatty acid based biofuels. Biotechnol. Biofuels 7, 7. doi:10.1186/1754-6834-7-7

Javidpour, P., Pereira, J.H., Goh, E.-B., McAndrew, R.P., Ma, S.M., Friedland, G.D., Keasling, J.D., Chhabra, S.R., Adams, P.D., Beller, H.R., 2014. Biochemical and structural studies of NADH-dependent FabG used to increase the bacterial production of fatty acids under anaerobic conditions. Appl. Environ. Microbiol. 80, 497-505. doi:10.1128/AEM.03194-13

Kaneda, T., 1991. Iso- and anteiso-fatty acids in bacteria: biosynthesis, function, and taxonomic significance. Microbiol. Mol. Biol. Rev. 55, 288-302.

Keasling, J.D., 2010. Manufacturing molecules through metabolic engineering. Science 330, 1355-8. doi:10.1126/science. 1193990

15 Khosla, C., Herschlag, D., Cane, D.E., Walsh, C.T., 2014. Assembly line polyketide synthases: mechanistic insights and unsolved problems. Biochemistry 53, 2875-83. doi:10.1021/bi500290t

Klug, L., Daum, G., 2014. Yeast lipid metabolism at a glance. FEMS Yeast Res. 14, 369-88. doi:10.1111/1567-1364.12141

20 Kocharin, K., Chen, Y., Siewers, V., Nielsen, J., 2012. Engineering of acetyl-CoA metabolism for the improved production of polyhydroxybutyrate in Saccharomyces cerevisiae. AMB Express 2, 52. doi:10.1186/2191-0855-2-52 
Krivoruchko, A., Serrano-Amatriain, C., Chen, Y., Siewers, V., Nielsen, J., 2013. Improving biobutanol production in engineered Saccharomyces cerevisiae by manipulation of acetylCoA metabolism. J. Ind. Microbiol. Biotechnol. 40, 1051-1056. doi:10.1007/s10295-013$1296-0$

5 Lennen, R.M., Braden, D.J., West, R.M., Dumesic, J.A., Pfleger, B.F., 2010. A process for microbial hydrocarbon synthesis: overproduction of fatty acids in Escherichia coli and catalytic conversion to alkanes. Biotechnol. Bioeng. 106, 193-202.

Lennen, R.M., Kruziki, M.A., Kumar, K., Zinkel, R.A., Burnum, K.E., Lipton, M.S., Hoover, S.W., Ranatunga, D.R., Wittkopp, T.M., Marner, W.D., others, 2011. Membrane stresses induced by overproduction of free fatty acids in Escherichia coli. Appl. Environ. Microbiol. $77,8114-8128$.

Lennen, R.M., Pfleger, B.F., 2012. Engineering Escherichia coli to synthesize free fatty acids. Trends Biotechnol. 30, 659-667. doi:10.1016/j.tibtech.2012.09.006

Lennen, R.M., Pfleger, B.F., 2013. Microbial production of fatty acid-derived fuels and chemicals. Curr. Opin. Biotechnol. 24, 1044-53. doi:10.1016/j.copbio.2013.02.028

Lennen, R.M., Politz, M.G., Kruziki, M.A., Pfleger, B.F., 2013. Identification of transport proteins involved in free fatty acid efflux in Escherichia coli. J. Bacteriol. 195, 135-144. doi:10.1128/JB.01477-12

Liu, P., Chernyshov, A., Najdi, T., Fu, Y., Dickerson, J., Sandmeyer, S., Jarboe, L., 2013. Membrane stress caused by octanoic acid in Saccharomyces cerevisiae. Appl. Microbiol. Biotechnol. 97, 3239-51. doi:10.1007/s00253-013-4773-5

Liu, T., Vora, H., Khosla, C., 2010. Quantitative analysis and engineering of fatty acid biosynthesis in E. coli. Metab. Eng. 12, 378-386. doi:10.1016/j.ymben.2010.02.003 
Liu, X., Sheng, J., Curtiss, R., 2011. Fatty acid production in genetically modified cyanobacteria. Proc. Natl. Acad. Sci. U. S. A. 108, 6899-904. doi:10.1073/pnas.1103014108

Lu, W., Ness, J.E., Xie, W., Zhang, X., Minshull, J., Gross, R.A., 2010. Biosynthesis of monomers for plastics from renewable oils. J. Am. Chem. Soc. 132, 15451-5. doi:10.1021/ja107707v

Lu, X., Vora, H., Khosla, C., 2008. Overproduction of free fatty acids in E. coli: implications for biodiesel production. Metab. Eng. 10, 333-9. doi:10.1016/j.ymben.2008.08.006

Mansilla, M.C., Cybulski, L.E., Albanesi, D., de Mendoza, D., 2004. Control of membrane lipid fluidity by molecular thermosensors. J. Bacteriol. 186, 6681-8. doi:10.1128/JB.186.20.6681-6688.2004

My, L., Rekoske, B., Lemke, J.J., Viala, J.P., Gourse, R.L., Bouveret, E., 2013. Transcription of the Escherichia coli fatty acid synthesis operon fabHDG is directly activated by FadR and inhibited by ppGpp. J. Bacteriol. 195, 3784-95. doi:10.1128/JB.00384-13

Na, D., Kim, T.Y., Lee, S.Y., 2010. Construction and optimization of synthetic pathways in metabolic engineering. Curr. Opin. Microbiol. 13, 363-70. doi:10.1016/j.mib.2010.02.004

OECD, 2014. OECD/Food and Agriculture Organization of the United Nations, in: OECD-FAO Agricultural Outlook 2014. OECD Publishing. doi:10.1787/agr_outlook-2014-en

Oilseeds: World Markets and Trade, 2014.

Orth, J.D., Conrad, T.M., Na, J., Lerman, J.A., Nam, H., Feist, A.M., Palsson, B.Ø., 2011. A comprehensive genome-scale reconstruction of Escherichia coli metabolism--2011. Mol. Syst. Biol. 7, 535. doi:10.1038/msb.2011.65 
Papanikolaou, S., Aggelis, G., 2002. Lipid production by Yarrowia lipolytica growing on industrial glycerol in a single-stage continuous culture. Bioresour. Technol. 82, 43-49. doi:10.1016/S0960-8524(01)00149-3

Peralta-Yahya, P.P., Zhang, F., del Cardayre, S.B., Keasling, J.D., 2012. Microbial engineering for the production of advanced biofuels. Nature 488, 320-328. doi:10.1038/nature11478

Polyak, S.W., Abell, a D., Wilce, M.C.J., Zhang, L., Booker, G.W., 2012. Structure, function and selective inhibition of bacterial acetyl-coa carboxylase. Appl. Microbiol. Biotechnol. 93, 983-92. doi:10.1007/s00253-011-3796-z

Radakovits, R., Jinkerson, R.E., Darzins, A., Posewitz, M.C., 2010. Genetic engineering of algae for enhanced biofuel production. Eukaryot. Cell 9, 486-501. doi:10.1128/EC.00364-09

Ranganathan, S., Tee, T.W., Chowdhury, A., Zomorrodi, A.R., Yoon, J.M., Fu, Y., Shanks, J. V, Maranas, C.D., 2012. An integrated computational and experimental study for overproducing fatty acids in Escherichia coli. Metab. Eng. 14, 687-704. doi:10.1016/j.ymben.2012.08.008

15 Rodriguez, G.M., Tashiro, Y., Atsumi, S., 2014. Expanding ester biosynthesis in Escherichia coli. Nat. Chem. Biol. 10, 259-65. doi:10.1038/nchembio.1476

Royce, L.A., Liu, P., Stebbins, M.J., Hanson, B.C., Jarboe, L.R., 2013. The damaging effects of short chain fatty acids on Escherichia coli membranes. Appl. Microbiol. Biotechnol. 97, 8317-27. doi:10.1007/s00253-013-5113-5

20 Ruffing, A.M., 2013. RNA-Seq analysis and targeted mutagenesis for improved free fatty acid production in an engineered cyanobacterium. Biotechnol. Biofuels 6, 113. doi:10.1186/1754-6834-6-113 
Ruffing, A.M., 2014. Improved Free Fatty Acid Production in Cyanobacteria with Synechococcus sp. PCC 7002 as Host. Front. Bioeng. Biotechnol. 2, 1-10. doi:10.3389/fbioe.2014.00017

Runguphan, W., Keasling, J.D., 2014. Metabolic engineering of Saccharomyces cerevisiae for production of fatty acid-derived biofuels and chemicals. Metab. Eng. 21, 103-113. doi:10.1016/j.ymben.2013.07.003

Schirmer, A., Rude, M. a, Li, X., Popova, E., del Cardayre, S.B., 2010. Microbial biosynthesis of alkanes. Science 329, 559-562. doi:10.1126/science.1187936

Sheehan, J., Dunahay, T., Benemann, J., Roessler, P., 1998. Look Back at the U.S. Department of Energy's Aquatic Species Program: Biodiesel from Algae; Close-Out Report. doi: $10.2172 / 15003040$

Sheibani, S., Richard, V.R., Beach, A., Leonov, A., Feldman, R., Mattie, S., Khelghatybana, L., Piano, A., Greenwood, M., Vali, H., Titorenko, V.I., 2014. Macromitophagy, neutral lipids synthesis, and peroxisomal fatty acid oxidation protect yeast from "liponecrosis", a previously unknown form of programmed cell death. Cell Cycle 13, 138-147. doi:10.4161/cc.26885

Shi, S., Chen, Y., Siewers, V., Nielsen, J., 2014a. Improving production of malonyl coenzyme A-derived metabolites by abolishing Snf1-dependent regulation of Acc1. MBio 5, e0113014. doi:10.1128/mBio.01130-14

Shi, S., Valle-Rodríguez, J.O., Siewers, V., Nielsen, J., 2011. Prospects for microbial biodiesel production. Biotechnol. J. 6, 277-285. doi:10.1002/biot.201000117

Shi, S., Valle-Rodríguez, J.O., Siewers, V., Nielsen, J., Valle-rodrı, J.O., 2014b. Engineering of chromosomal wax ester synthase integrated Saccharomyces cerevisiae mutants for 
improved biosynthesis of fatty acid ethyl esters. Biotechnol. Bioeng. 111, 1740-7. doi:10.1002/bit.25234

Shiba, Y., Paradise, E.M., Kirby, J., Ro, D.-K., Keasling, J.D., 2007. Engineering of the pyruvate dehydrogenase bypass in Saccharomyces cerevisiae for high-level production of isoprenoids. Metab. Eng. 9, 160-168. doi:10.1016/j.ymben.2006.10.005

Soma, Y., Tsuruno, K., Wada, M., Yokota, A., Hanai, T., 2014. Metabolic flux redirection from a central metabolic pathway toward a synthetic pathway using a metabolic toggle switch. Metab. Eng. 23, 175-84. doi:10.1016/j.ymben.2014.02.008

Steen, E.J., Kang, Y., Bokinsky, G., Hu, Z., Schirmer, A., McClure, A., Del Cardayre, S.B., Keasling, J.D., 2010. Microbial production of fatty-acid-derived fuels and chemicals from plant biomass. Nature 463, 559-62. doi:10.1038/nature08721

Tai, M., Stephanopoulos, G., 2013. Engineering the push and pull of lipid biosynthesis in oleaginous yeast Yarrowia lipolytica for biofuel production. Metab. Eng. 15, 1-9. doi:10.1016/j.ymben.2012.08.007

15 Tehlivets, O., Scheuringer, K., Kohlwein, S.D., 2007. Fatty acid synthesis and elongation in yeast. Biochim. Biophys. Acta 1771, 255-270. doi:10.1016/j.bbalip.2006.07.004

Torella, J.P., Ford, T.J., Kim, S.N., Chen, A.M., Way, J.C., Silver, P. a, 2013. Tailored fatty acid synthesis via dynamic control of fatty acid elongation. Proc. Natl. Acad. Sci. U. S. A. 110, 11290-5. doi:10.1073/pnas.1307129110

20 Tseng, H.-C., Prather, K.L.J., 2012. Controlled biosynthesis of odd-chain fuels and chemicals via engineered modular metabolic pathways. Proc. Natl. Acad. Sci. U. S. A. 109, 17925-30. doi:10.1073/pnas.1209002109 
Tsigie, Y.A., Wang, C.-Y., Truong, C.-T., Ju, Y.-H., 2011. Lipid production from Yarrowia lipolytica Po1g grown in sugarcane bagasse hydrolysate. Bioresour. Technol. 102, 9216-22. doi:10.1016/j.biortech.2011.06.047

Valle-Rodríguez, J.O., Shi, S., Siewers, V., Nielsen, J., 2014. Metabolic engineering of

5 Saccharomyces cerevisiae for production of fatty acid ethyl esters, an advanced biofuel, by eliminating non-essential fatty acid utilization pathways. Appl. Energy 115, 226-232. doi:10.1016/j.apenergy.2013.10.003

Voelker, T.A., Davies, H.M., 1994. Alteration of the specificity and regulation of Alteration of the Specificity and Regulation of Fatty Acid Synthesis of Escherichia coli by Expression of a Plant Medium- Chain Acyl-Acyl Carrier Protein Thioesterase.

Wältermann, M., Steinbüchel, A., Wa, M., Steinbu, A., 2005. Neutral Lipid Bodies in Prokaryotes : Recent Insights into Structure, Formation, and Relationship to Eukaryotic Lipid Depots MINIREVIEW Neutral Lipid Bodies in Prokaryotes: Recent Insights into Structure , Formation , and Relationship to Eukaryotic Lip 187. doi:10.1128/JB.187.11.3607

Wang, W., Lu, X., 2013. Microbial Synthesis of Alka(e)nes. Front. Bioeng. Biotechnol. 1, 10. doi:10.3389/fbioe.2013.00010

Wijffels, R.H., Barbosa, M.J., 2010. An outlook on microalgal biofuels. Science 329, 796-9. doi:10.1126/science.1189003

20 Willis, R.M., Wahlen, B.D., Seefeldt, L.C., Barney, B.M., 2011. Characterization of a Fatty Acyl-CoA Reductase from Marinobacter aquaeolei VT8: A Bacterial Enzyme Catalyzing the Reduction of Fatty Acyl-CoA to Fatty Alcohol. 
Winters, K., Parker, P.L., Van Baalen, C., 1969. Hydrocarbons of blue-green algae: geochemical signfficance. Science 163, 467-8. doi:10.1126/science.163.3866.467

Wong, F.T., Khosla, C., 2012. Combinatorial biosynthesis of polyketides--a perspective. Curr. Opin. Chem. Biol. 16, 117-23. doi:10.1016/j.cbpa.2012.01.018

5 Woolston, B.M., Edgar, S., Stephanopoulos, G., 2013. Metabolic engineering: past and future. Annu. Rev. Chem. Biomol. Eng. 4, 259-88. doi:10.1146/annurev-chembioeng-061312103312

Wu, H., San, K.-Y., 2014. Efficient odd straight medium chain free fatty acid production by metabolically engineered Escherichia coli. Biotechnol. Bioeng. 111, 2209-19. doi:10.1002/bit.25296

Xu, P., Li, L., Zhang, F., Stephanopoulos, G., Koffas, M., 2014. Improving fatty acids production by engineering dynamic pathway regulation and metabolic control. Proc. Natl. Acad. Sci. 111, 1-6. doi:10.1073/pnas.1406401111

Xu, P., Ranganathan, S., Fowler, Z.L., Maranas, C.D., Koffas, M.A.G., 2011. Genome-scale metabolic network modeling results in minimal interventions that cooperatively force carbon flux towards malonyl-CoA. Metab Eng 13, 578-587. doi:10.1016/j.ymben.2011.06.008

Youngquist, J.T., Rose, J.P., Pfleger, B.F., 2013a. Free fatty acid production in Escherichia coli under phosphate-limited conditions. Appl. Microbiol. Biotechnol. 97, 5149-59. doi:10.1007/s00253-013-4911-0

Youngquist, J.T., Schumacher, M.H., Rose, J.P., Raines, T.C., Politz, M.C., Copeland, M.F., Pfleger, B.F., 2013b. Production of medium chain length fatty alcohols from glucose in $<\mathrm{i}>$ Escherichia coli</i>. Metab. Eng. 20, 177-186. doi:10.1016/j.ymben.2013.10.006 
Zanghellini, A., 2014. De Novo Computational Enzyme Design. Curr. Opin. Biotechnol. 29C, 132-138. doi:10.1016/j.copbio.2014.03.002

Zha, W., Rubin-Pitel, S.B., Shao, Z., Zhao, H., 2009. Improving cellular malonyl-CoA level in Escherichia coli via metabolic engineering. Metab. Eng. 11, 192-8. doi:10.1016/j.ymben.2009.01.005

Zhang, F., Carothers, J.M., Keasling, J.D., 2012a. Design of a dynamic sensor-regulator system for production of chemicals and fuels derived from fatty acids. Nat. Biotechnol. 30, 354359. doi:10.1038/nbt.2149

Zhang, F., Ouellet, M., Batth, T.S., Adams, P.D., Petzold, C.J., Mukhopadhyay, A., Keasling, J.D., 2012b. Enhancing fatty acid production by the expression of the regulatory transcription factor FadR. Metab. Eng. 14, 653-60. doi:10.1016/j.ymben.2012.08.009

Zhang, K., Sawaya, M.R., Eisenberg, D.S., Liao, J.C., 2008. Expanding metabolism for biosynthesis of nonnatural alcohols. Proc. Natl. Acad. Sci. U. S. A. 105, 20653-20658. doi:10.1073/pnas.0807157106

15 Zhang, Y.-M., Rock, C.O., 2008. Membrane lipid homeostasis in bacteria. Nat. Rev. Microbiol. 6, 222-33. doi:10.1038/nrmicro1839

Zhang, Y.-M., Rock, C.O., 2009. Transcriptional regulation in bacterial membrane lipid synthesis. J. Lipid Res. 50 Suppl, S115-9. doi:10.1194/jlr.R800046-JLR200

Zhou, Y.J., Buijs, N. a., Siewers, V., Nielsen, J., 2014. Fatty Acid-Derived Biofuels and Chemicals Production in Saccharomyces cerevisiae. Front. Bioeng. Biotechnol. 2, 1-6. doi:10.3389/fbioe.2014.00032 
Zhuang, Q., Wang, Q., Liang, Q., Qi, Q., 2014. Synthesis of polyhydroxyalkanoates from glucose that contain medium-chain-length monomers via the reversed fatty acid $\beta$-oxidation cycle in Escherichia coli. Metab. Eng. 24, 78-86. doi:10.1016/j.ymben.2014.05.004 


\section{Figure Captions}

\section{Figure 1. Oils \& fats are currently the primary feedstock for oleochemical}

production. Free fatty acids and fatty acid esters are the raw materials used to synthesize oleochemicals. These intermediates are produced by saponification or transesterification of oils and fats, respectively. Fatty acid esters are used as biodiesel, a renewable transportation fuel with properties comparable to conventional petrodiesel. Fatty acid esters and free fatty acids are converted to fatty alcohols or fatty amines which are intermediates for production of various surfactants such as fatty alcohol sulfates and fatty alcohol ethoxysulfates (anionic) or fatty alcohol ethoxylates and fatty amine oxides (non-ionic). Engineered microbes have the potential to produce many of the intermediates in this scheme from renewable resources. These microbes are either directly photoautotrophic or use plant biomass as a feedstock (such as lignocellulosic sugars).

Figure 2. Oleochemical Metabolism. The molecular features of oleochemicals (e.g. molecular weight, carbon number, methylene content, branching, hydroxylation, terminal group)

15 are controlled through one of four processes. Initiation controls carbon number and branching. Elongation controls the chain length and incorporation of internal substitutions. Termination determines the class of oleochemical (acid, ester, aldehyde, alcohol, olefin, alkane). Modification involves introduction of double bonds, hydroxyl groups, and branching post synthesis of the main alkyl chain.

Figure 3. Oleochemical economics. a.) The maximum theoretical yield of each oleochemical from glucose was calculated by performing flux balance analysis on a modified version of an E. coli genome scale metabolic model (iJO1366 (Orth et al., 2011) supplemented with reactions comprising the thiolase pathway and the rage of termination reactions described in 
3.4). Oleochemical selling prices were obtained from January 29, 2014 pricing reports provided by ISIS. b.-d.) The impact of sugar price on process economics was demonstrated by plotting the gross margin based on only feedstock costs. The Y-axis was calculated by subtracting the cost of glucose needed to make $1 \mathrm{lb}$ of oleochemical from the oleochemical selling price and dividing it

5 by the oleochemical selling price. Average theoretical yields were used for products containing multiple species. Abbreviations: FAEE - fatty acid ethyl ester; FAME - fatty acid methyl ester; AAce - acetate acyl ester; Alk - alkane; MK - methyl-ketone.

Figure 4. Successful Metabolic Engineering Strategies. a). List of general strategies. b.) Gene deletions and c.) transient removal of enzymes can be used to block flux from unwanted

10 pathways. d.) In E. coli, deregulation is accomplished by expression of a thioesterase which shunts flux away from long-chain acyl-ACP, the key regulatory signal. e.) Maximal production of oleochemicals often requires optimized, not maximal, expression of rate limiting enzymes (titration of a thioesterase is shown). f.) Dynamic control strategies such as using FadR to sense acyl-CoA levels have been used to balance the synthesis of individual co-substrates. g.) Genome

15 scale metabolic models have been used to identify global strategies for balancing co-factor utilization and maximizing flux to desired oleochemicals.

Figure 5. Current challenges in microbial oleochemical production. Economically viable production of oleochemicals in engineered microbes will require improvement of several critical aspects, e.g. abolishing feedback inhibition, optimizing substrate specificity by changing

20 chain-length preference, balancing redox balance by changing cofactor preference, improving intracellular storage and/or introducing high-efflux transporters for efficient secretion of the final product.

\section{Figures}




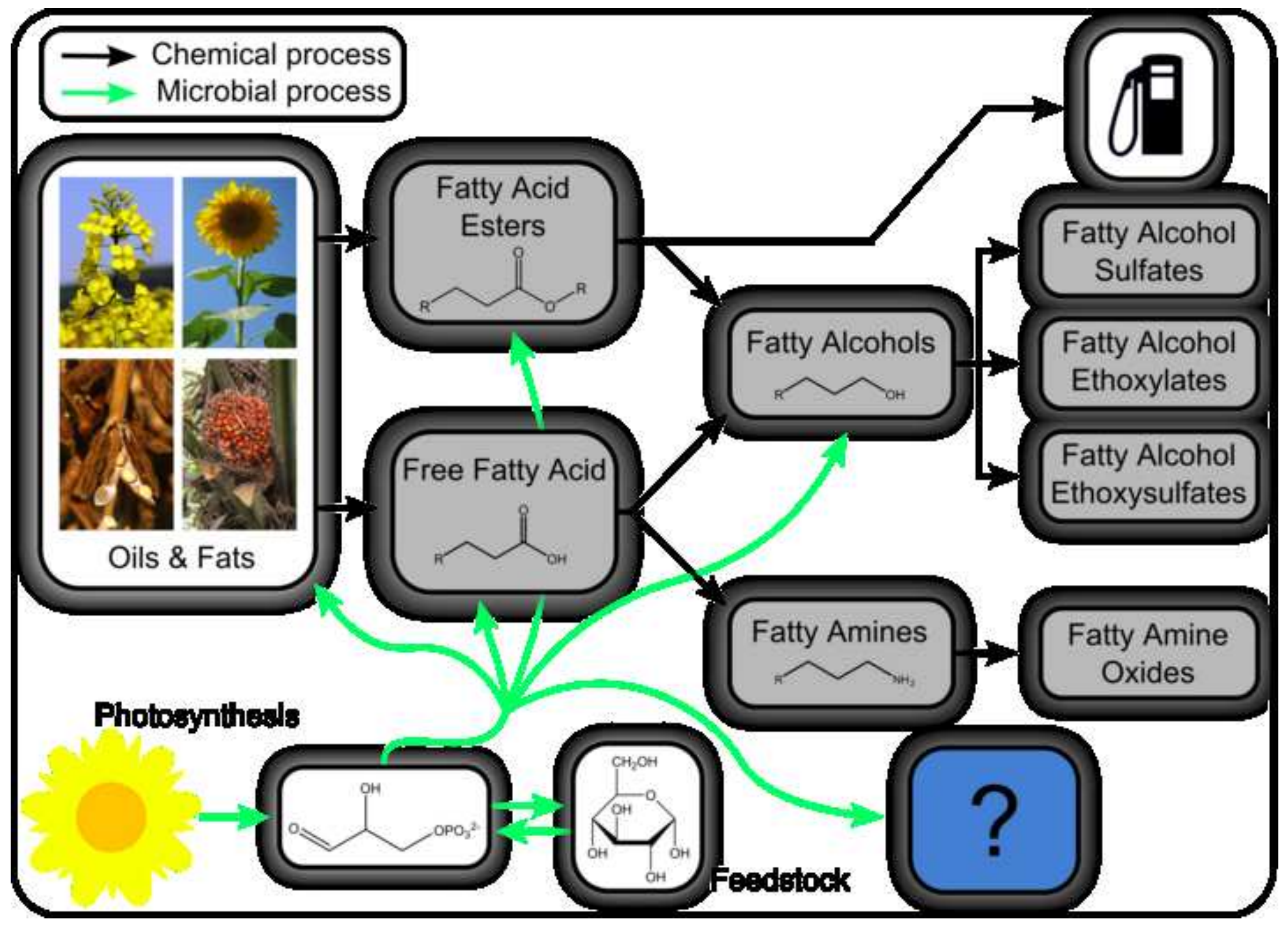




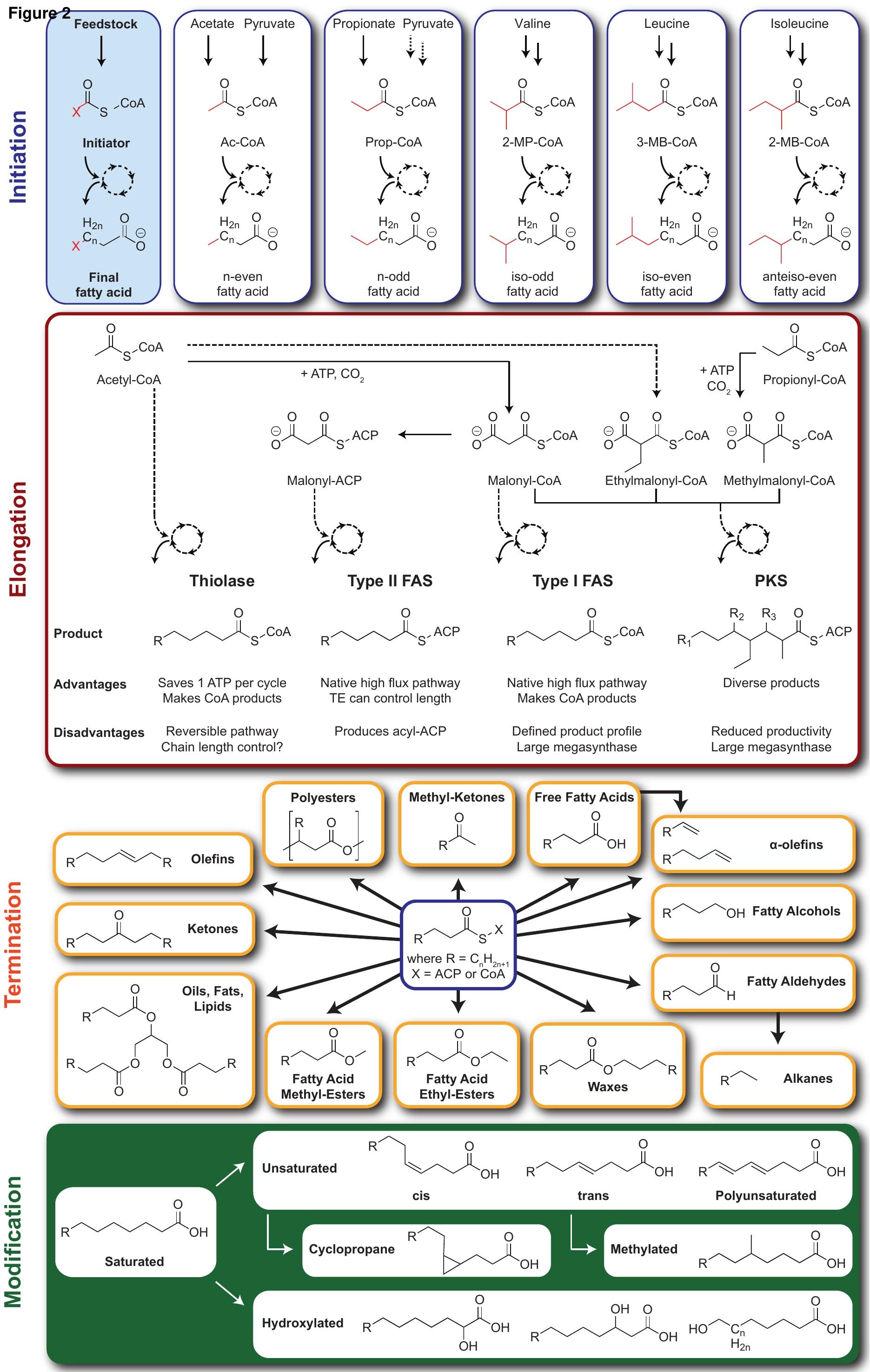




\section{Flgure 3}

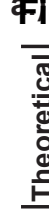

\begin{tabular}{|c|c|c|c|}
\hline 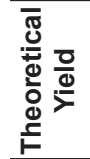 & $\begin{array}{r}\text { Acyl-Chain } \\
\mathrm{mol} / \mathrm{mol} \\
\mathrm{g} / \mathrm{g}\end{array}$ & $\begin{array}{r}\text { C16 } \\
0.203 \\
0.305\end{array}$ & $\begin{array}{r}\text { C16 } \\
0.231 \\
0.364\end{array}$ \\
\hline \multicolumn{4}{|c|}{ Jan '14 price per lb } \\
\hline ๑.) & $\begin{array}{r}\text { B } \\
-\mathrm{F} \\
-\mathrm{Al}\end{array}$ & $\begin{array}{l}\text { IODI } \\
\text { EE - }\end{array}$ & $\begin{array}{l}E \mathbf{L} \\
--\mathrm{AAcE}\end{array}$ \\
\hline
\end{tabular}

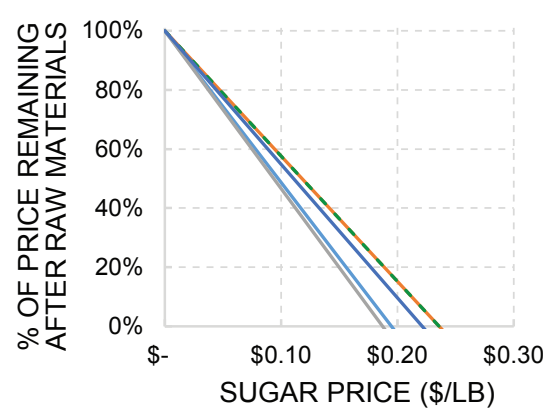

$\begin{array}{lllll}\text { AAcE } & \text { Alkane } & \text { Methyl-Ketone } & \text { Free Fatty Acid } & \text { Fatty Alcohol }\end{array}$

\begin{tabular}{crrrrrrrrr} 
C16 & C15 & C14 & C8 & C12 & C16 & C8 & C12 & C16 \\
0.231 & 0.250 & 0.273 & 0.545 & 0.353 & 0.261 & 0.500 & 0.333 & 0.250 \\
0.364 & 0.295 & 0.343 & 0.437 & 0.392 & 0.371 & 0.361 & 0.345 & 0.336 \\
\hline
\end{tabular}

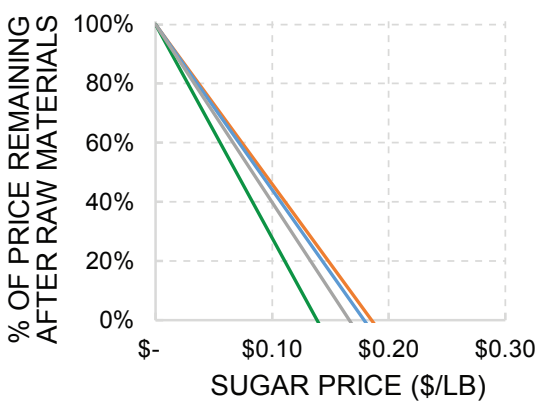

c.) SUGAR PRICE (\$/LB) d.)

FATTY ALCOHOLS

$-\mathrm{C} 8-\mathrm{C} 10-\mathrm{C} 12-\mathrm{C} 14$

$-\mathrm{C} 16-\mathrm{C} 16-\mathrm{C} 18-\mathrm{C} 18$
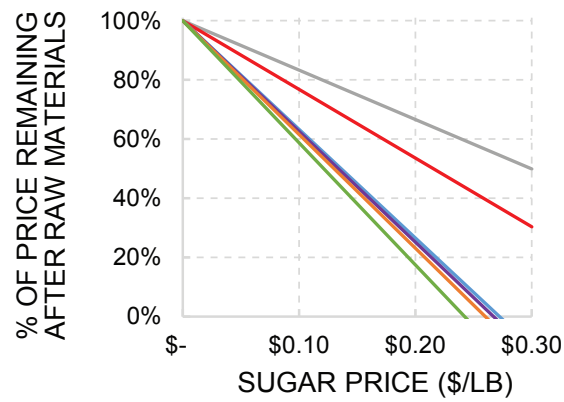


\section{Figure 4}

a. General Metabolic Engineeirng Strategy

1. Block competing pathways and futile cycles

2. Provide strong, irreversible pull toward desired product

3. Deregulate fatty acid biosynthesis

4. Balance co-factors, reducing power, and enzyme activity

5. Push carbon flux into acetyl-CoA and fatty acid biosynthesis

6 . Remove or sequester products to avoid toxicity

b. Block Competing Pathways<smiles>CC(=O)C(=O)O</smiles><smiles>C1CCCC1</smiles>

O<smiles>C=C(C)SC(=O)O</smiles>
Acetyl-CoA

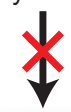<smiles>CC(O)C(=O)[O-]</smiles><smiles>CCOC(C)C(=O)O</smiles>

Alternative

Products

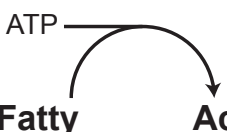

Acid

Acyl-

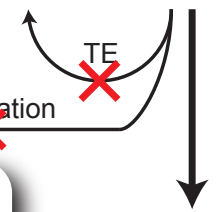

$\beta$-Oxidation

Oleochemical

Product

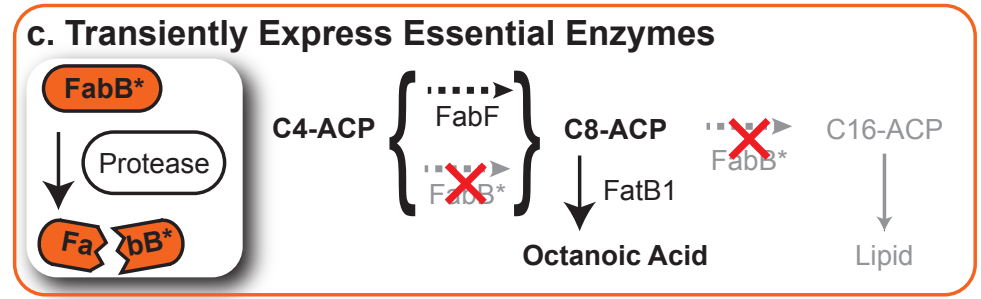

\section{d. Dergulate Fatty Acid Biosynthesis and Maximize Pathway Activity}

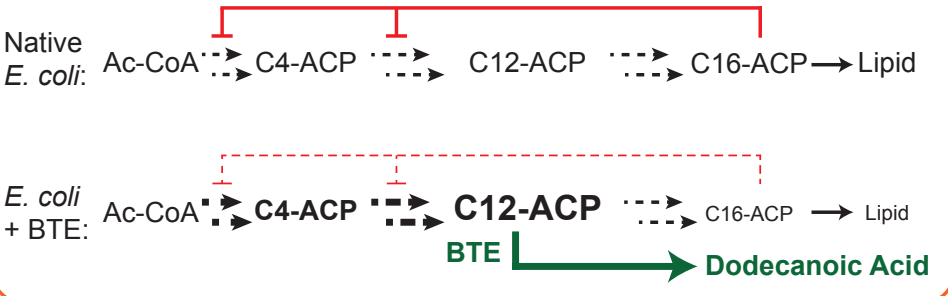

e. Optimize Enzyme Expression or Activity
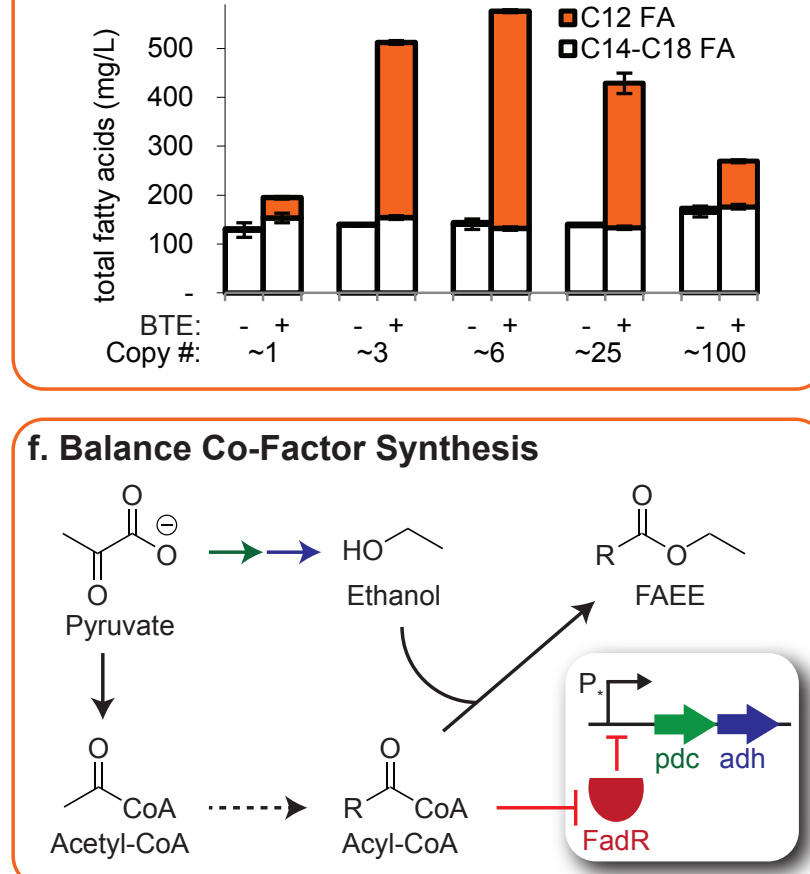

\section{g. Balance Reducing Power}

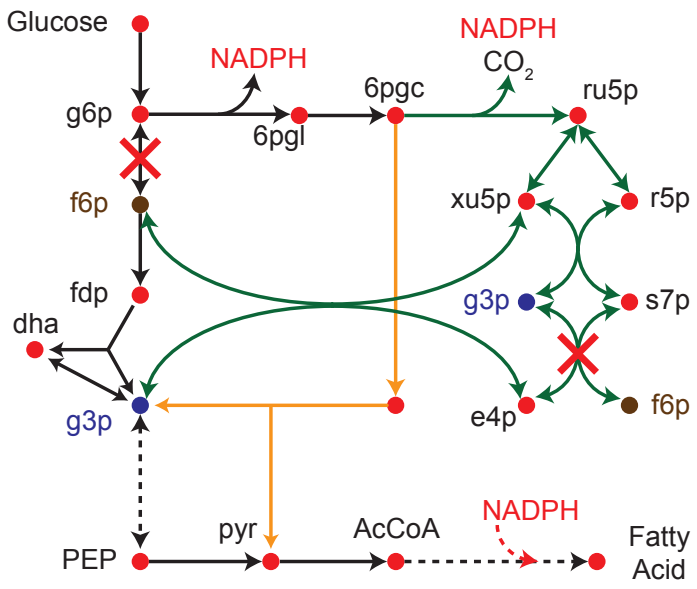




\section{Introduce}

high-efflux transporter

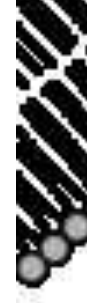

1.

Lipid biosynthesis 11 , 1 ,

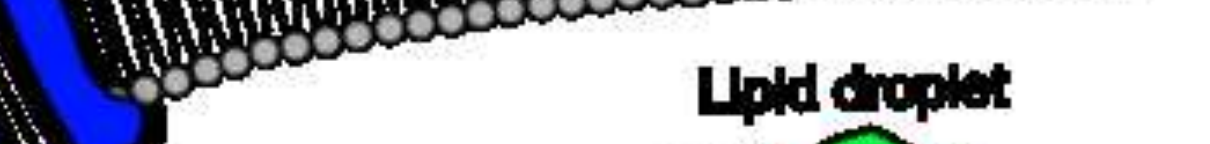

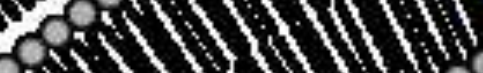

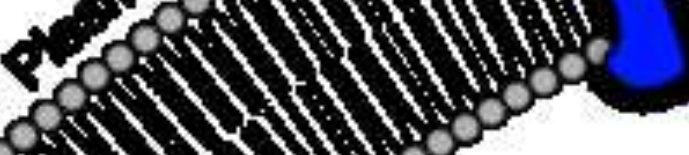

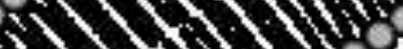

1

(1)

(1)
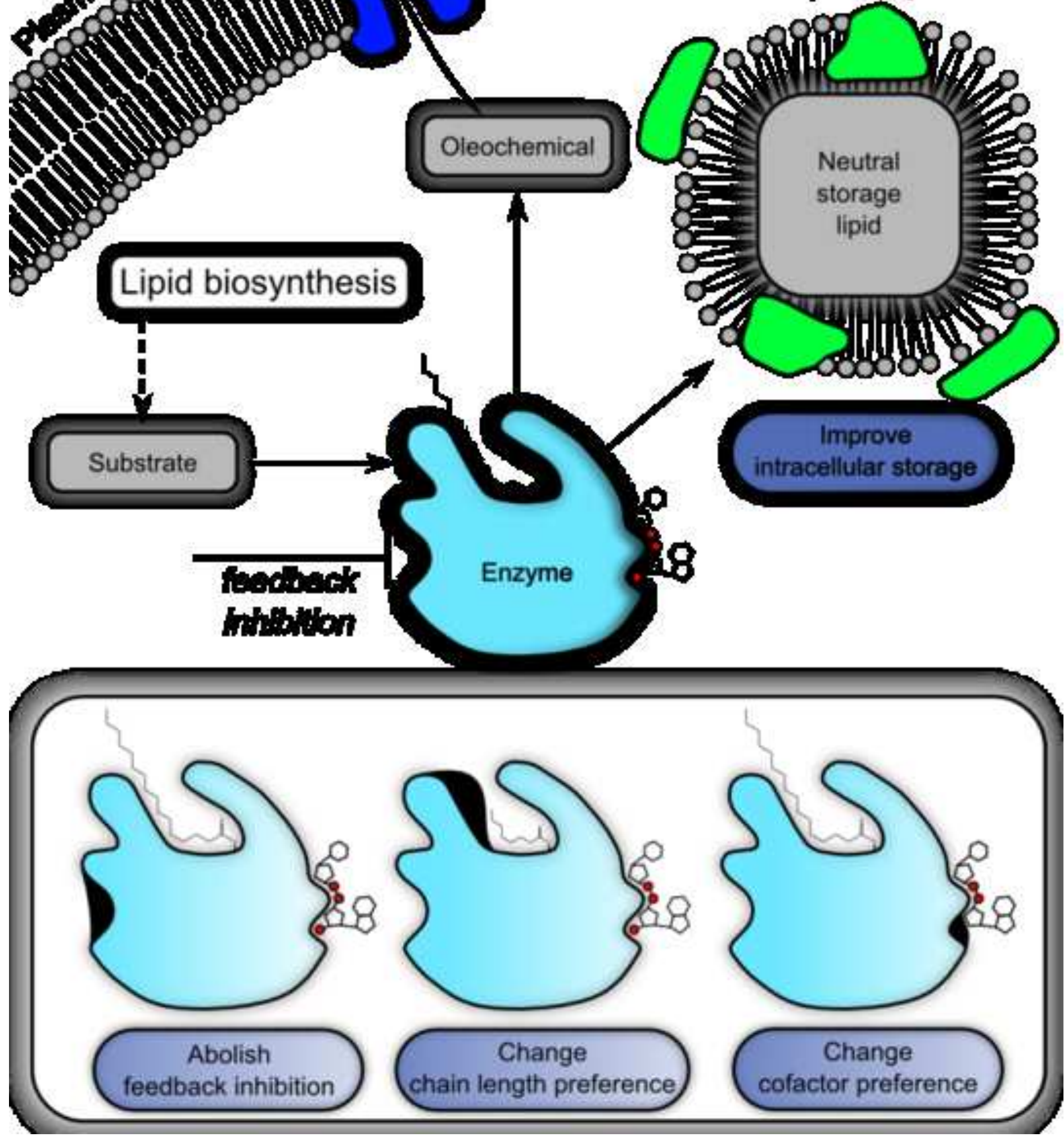